\title{
An Idealized Model of Weddell Gyre Export Variability
}

\author{
ZHAN SU \\ Division of Geological and Planetary Sciences, California Institute of Technology, Pasadena, California \\ ANDREW L. STEWART AND ANDREW F. THOMPSON \\ Environmental Science and Engineering, California Institute of Technology, Pasadena, California
}

(Manuscript received 4 December 2013, in final form 14 February 2014)

\begin{abstract}
Recent observations suggest that the export of Antarctic Bottom Water (AABW) from the Weddell Sea has a seasonal cycle in its temperature and salinity that is correlated with annual wind stress variations. This variability has been attributed to annual vertical excursions of the isopycnals in the Weddell Gyre, modifying the water properties at the depth of the Orkney Passage. Recent studies attribute these variations to locally wind-driven barotropic dynamics in the northern Weddell Sea boundary current. This paper explores an alternative mechanism in which the isopycnals respond directly to surface Ekman pumping, which is coupled to rapidly responding mesoscale eddy buoyancy fluxes near the gyre boundary. A conceptual model of the interface that separates Weddell Sea Deep Water from Circumpolar Deep Water is described in which the bounding isopycnal responds to a seasonal oscillation in the surface wind stress. Different parameterizations of the mesoscale eddy diffusivity are tested. The model accurately predicts the observed phases of the temperature and salinity variability in relationship to the surface wind stress. The model, despite its heavy idealization, also accounts for more than $50 \%$ of the observed oscillation amplitude, which depends on the strength of the seasonal wind variability and the parameterized eddy diffusivity. These results highlight the importance of mesoscale eddies in modulating the export of AABW in narrow boundary layers around the Antarctic margins.
\end{abstract}

\section{Introduction}

Observations show that the properties of Antarctic Bottom Water (AABW) in the Weddell Sea's northern boundary current undergo a seasonal cycle in temperature and salinity (Gordon et al. 2010; McKee et al. 2011) at a fixed depth. This variability is found upstream of a key export site, the Orkney Passage (OP). Evidence of a link between this property variation and surface wind forcing is given by Jullion et al. (2010), who find that Weddell Sea Deep Water (WSDW) properties in the Scotia Sea correlate with local wind stress variation along the South Scotia Ridge with a phase lag of 5 months. Meredith et al. (2011) similarly find that temperature anomalies of WSDW in the Scotia Sea, and at the entrance of the Orkney Passage, lag the local surface

Corresponding author address: Zhan Su, Division of Geological and Planetary Sciences, California Institute of Technology, 1200 East California Blvd., Pasadena, CA 91125.

E-mail: zssu@caltech.edu wind stress by $2-4$ months. This study presents a mechanism to describe these observed time lags.

Here we focus on the transit of WSDW through the Weddell Gyre (Fig. 1), an important component of the global circulation. A significant fraction of AABW, which ventilates the deep ocean, originates as WSDW, which is typically defined as having a neutral density greater than $\gamma^{n} \sim 28.26 \mathrm{~kg} \mathrm{~m}^{-3}$ (Naveira Garabato et al. 2002). WSDW circulates cyclonically around the Weddell Gyre (Fig. 1b) (Deacon 1979) with the strongest velocities found within narrow boundary currents (Fig. 1d). As this boundary current intersects the South Scotia Ridge, WSDW may flow through deep passages and enter the Scotia Sea (Locarnini et al. 1993). Naveira Garabato et al. (2002) measure the lowered acoustic Doppler current profiler (LADCP)-referenced geostrophic transport of WSDW to be $6.7 \pm 1.7$ Sverdrups $\left(\mathrm{Sv} ; 1 \mathrm{~Sv} \equiv 10^{6} \mathrm{~m}^{3} \mathrm{~s}^{-1}\right)$ through the South Scotia Ridge (this value is modified to $4.7 \pm 0.7 \mathrm{~Sv}$ by their box inverse model of the western Weddell Gyre). The majority of this outflow, around 4-6 Sv of WSDW colder than $0^{\circ} \mathrm{C}$, traverses the Orkney 
(a)

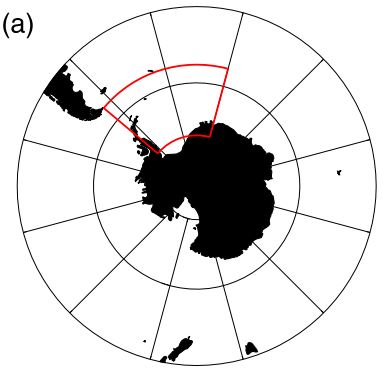

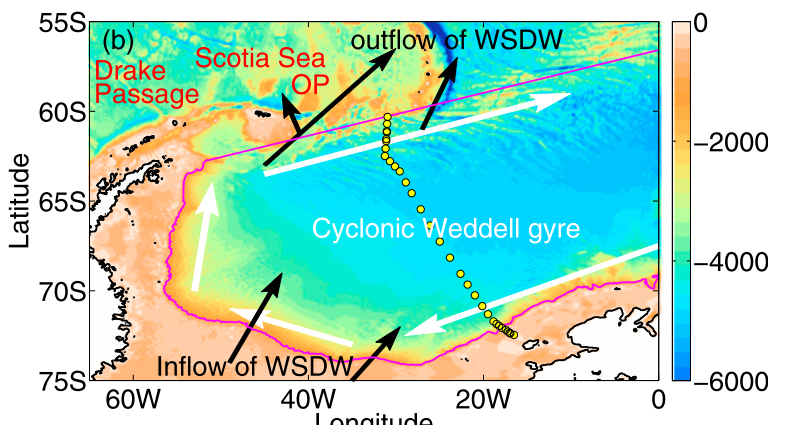

Longitude
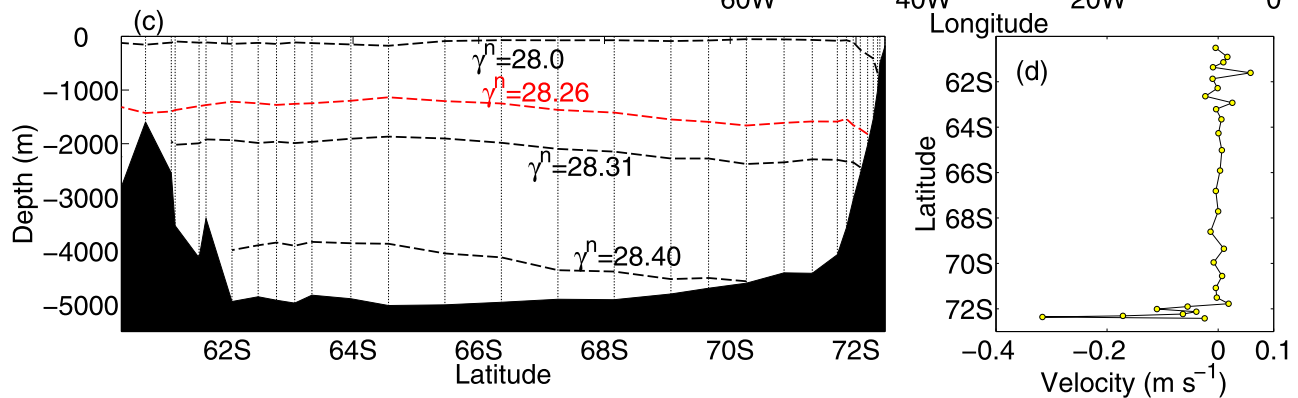

FIG. 1. (a) Map of the Southern Ocean. The highlighted region is enlarged in (b). (b) Bathymetry (ETOPO1) of the Weddell Sea and neighboring basins $(\mathrm{m})$; land is marked by black contours. The white arrows depict the cyclonic gyre circulation. The black arrows depict the inflow of WSDW and primary outflow paths of WSDW through OP in the South Scotia Ridge. The magenta contour indicates the 1000-m isobath in the southern and western part of the gyre. The northern boundary is approximated by a straight line. The yellow circles mark the position of the World Ocean Circulation Experiment (WOCE) A23 hydrographic section, indicated by dotted lines in (c). (c) Contours of neutral density from A23. The red curve with $\gamma^{n}=28.26 \mathrm{~kg} \mathrm{~m}^{-3}$ serves as the focus of this study, as it separates WSDW from the CDW above. (d) Depth-averaged geostrophic velocity across A23, referenced to zero velocity at the surface.

Passage and merges with the Antarctic Circumpolar Current (ACC) (Meredith et al. 2008; Naveira Garabato et al. 2002).

The correlation between surface winds and WSDW export suggests an adjustment of the structure of the Weddell Gyre stratification to a modified surface wind stress curl. At large scales, the circulation of the Weddell Gyre is consistent with the Sverdrup balance; the negative surface wind stress curl leads to a southward transport in the gyre interior that is balanced by a northward return flow in a western boundary current (Gordon et al. 1981; Muench and Gordon 1995). Radiation of Rossby waves is a key mechanism by which a gyre-like flow responds to changes in wind forcing. For a Weddell Sea-sized basin, the barotropic component of the gyre circulation can adjust over a time scale of a few days, but the baroclinic component requires several years because the barotropic and baroclinic Rossby wave speeds differ by from three to four orders of magnitude (Anderson and Gill 1975). Therefore, it seems that baroclinic adjustment of the gyre via linear waves occurs too slowly to explain the annual variations of WSDW outflow properties. Appreciating this problem, recent work has ascribed the WSDW export variability to barotropic processes occurring within the boundary current of the northwestern Weddell Sea, in particular changes in bottom Ekman layer transport near the Orkney Passage (Jullion et al. 2010; Meredith et al. 2011).

Despite the relatively weak flows throughout the gyres, the circulation remains turbulent and, especially in the western boundary layer, mesoscale eddies make a leading contribution to the exchanges of mass, heat, and salt across the Antarctic shelf break (Nøst et al. 2011; Dinniman et al. 2011; Stewart and Thompson 2013). In this study we propose that mesoscale eddies, arising through the baroclinic instability that extracts potential energy from vertical isopycnal displacements related to the divergence and convergence in the surface Ekman forcing, are crucial in setting the buoyancy distribution of the Weddell Gyre. To test this hypothesis, we develop a conceptual model of the isopycnal separating WSDW from the overlying Circumpolar Deep Water (CDW) in the Weddell Sea. Furthermore, we cast this balance between wind- and eddy-induced circulations in the framework of residual-mean theory (RMT) (Andrews et al. 1987; Plumb and Ferrari 2005).

RMT has been an important tool in understanding the principal balances in the ACC's upper overturning cell (Marshall and Radko 2003) and has recently been extended to flows around the Antarctic margins (Stewart 

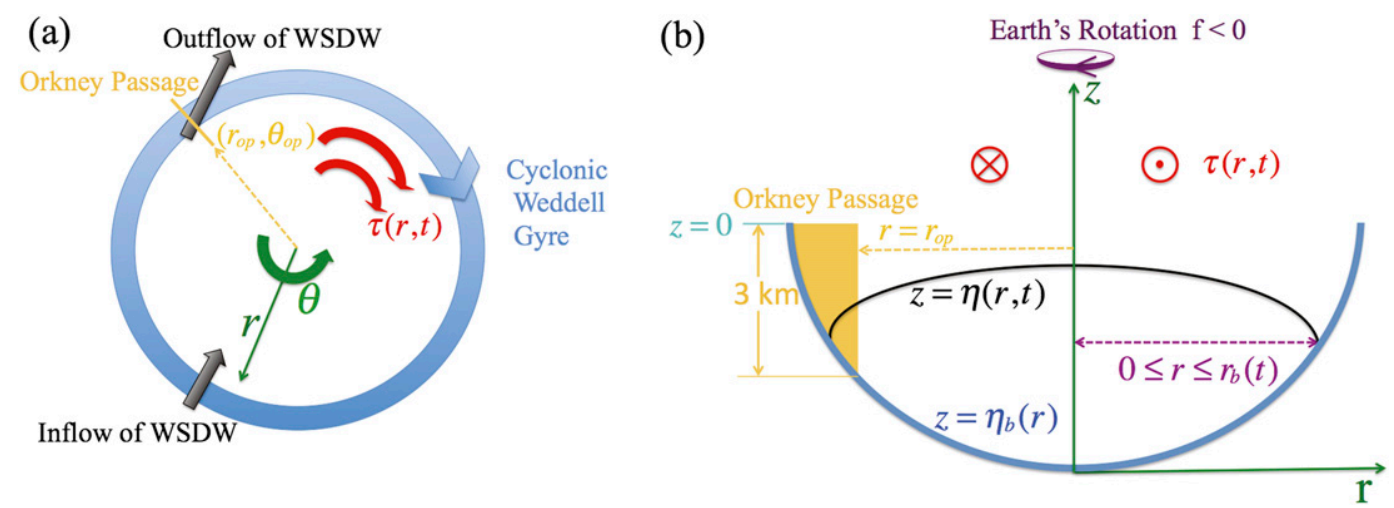

FIG. 2. Schematic of the idealized Weddell Gyre used in our residual-mean model. (a) The gyre is approximated as a circular basin with cyclonic surface wind stress $\tau(r, t)$ and forced by inflow and outflow of WSDW. (b) Profile view of the idealized gyre in cylindrical coordinates. The gyre bathymetry (blue) is described by $z=\eta_{b}(r)$ and the bounding isopycnal (black) is described by $z=\eta(r, t)$, marking the interface between CDW and WSDW, at a depth of roughly $1500 \mathrm{~m}$. The isopycnal intersects the bathymetry at $r=r_{b}(t)$. The yellow box indicates the cross-sectional area through which water exits the Orkney Passage, which extends to around 3-km depth (see, e.g., Fig. 7 of Naveira Garabato et al. 2002).

and Thompson 2013). This model moves away from the traditional picture that cross-shelf exchange requires large-scale along-shelf pressure gradients (Ou 2007). Here, we consider along-stream or tangentially averaged properties along the boundary of the Weddell Gyre. RMT is used to describe the evolution of the mean isopycnals in response to the annual variations of the wind stress. This approach is motivated in part by the striking isopycnal tilt seen in observations of the gyre boundary (Naveira Garabato et al. 2002).

In section 2, we describe our idealized domain and forcing, and in section 3, we derive a residual-mean model for the isopycnal bounding WSDW in the Weddell Gyre. In section 4 , we solve the evolution equation for the bounding isopycnal and discuss its sensitivity to wind stress and eddy diffusivity. In section 5 , we extend the model to include a representation of WSDW inflow to and outflow from the gyre. In section 6 , we compare our model predictions with observations and discuss the limitations and implications of our model. We draw conclusions in section 7 .

\section{An idealized Weddell Gyre}

Our approach adopts an idealized version of the Weddell Gyre that captures key aspects of the physics controlling isopycnal variability. Figure 2 shows a schematic of our conceptual model. The gyre is assumed to be circular and azimuthally uniform with an applied azimuthally uniform surface wind stress. This geometry motivates a description in terms of cylindrical coordinates $(r, \theta, z)$, where $r=0$ at the gyre center, $r=R=680 \mathrm{~km}$ at the gyre edge, and $\theta$ is anticyclonic.
To explore the properties of WSDW exported from the edge of the Weddell Gyre, the model focuses on the evolution of an isopycnal that represents the division between WSDW and CDW (Fig. 1c). The model solves for the isopycnal's azimuthal-mean position $z=\eta(r, t)$ as a function of radius $r$ and time $t$. The position at which this isopycnal outcrops from the bathymetry is denoted as $r=r_{b}(t)$.

\section{a. Bathymetry}

The idealized bathymetry is derived from the National Oceanic and Atmospheric Administration (NOAA) Earth Topography Digital Dataset 1 arc-minute (ETOPO1) global relief model data (Amante and Eakins 2009) shown in Fig. 1b. The 1-km depth contour (magenta curve) defines the southern and western boundary of the Weddell Gyre. At the northern edge of the gyre the 1-km isobath is discontinuous, and we use a straight line to approximate the boundary.

We construct the model bathymetry as an average of 75 evenly spaced sections that extend perpendicularly from the shelf break into the gyre interior (not shown). The sections are chosen to be $680 \mathrm{~km}$ long so that they meet approximately in the gyre center. This produces a smooth representation of the bathymetry, but realistically captures the slope, especially around the gyre edge (Fig.3). A simple polynomial approximation is also provided by the solid curve in Fig. 3:

$$
\eta_{b}(r)=C_{0}+C_{5} r^{5},
$$

with coefficients $C_{0}=-4.54 \times 10^{3} \mathrm{~m}$ and $C_{5}=1.85 \times$ $10^{-26} \mathrm{~m}^{-4}$. 


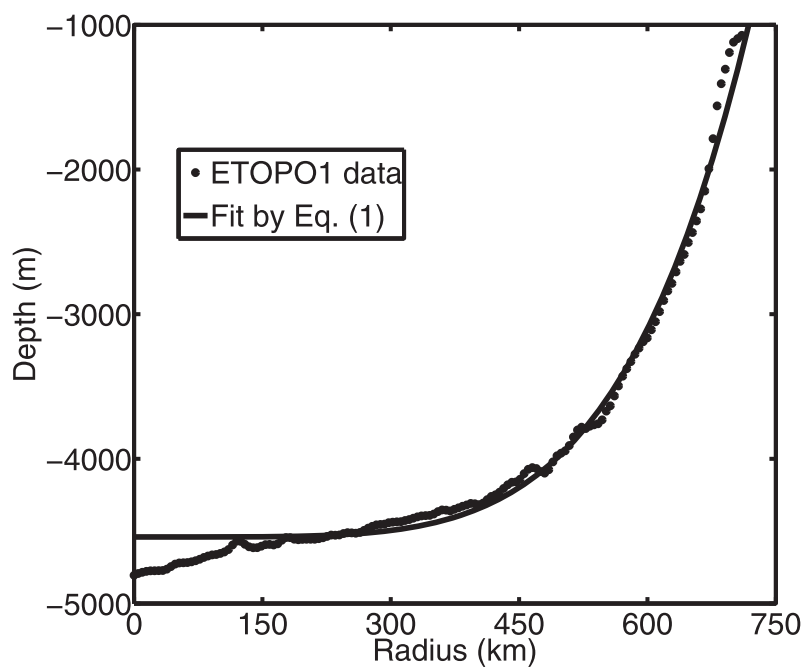

FIG. 3. The tangentially averaged basin geometry of the Weddell Sea from ETOPO1 data (points) and an analytical fit $\eta_{b}(r)$ (line) given by (1).

\section{b. Azimuthal winds}

Wind stress amplitudes over the Weddell Gyre are poorly constrained by observations. We choose to adopt a simple representation of the wind stress (described below) and explore the sensitivity to this choice in section $4 \mathrm{c}$. The wind stress profiles are derived from the Coordinated Ocean-Ice Reference Experiments, version 2 (CORE.v2 global air-sea flux dataset (Large and Yeager 2009), available from 1949 to 2006 with a monthly frequency and $1^{\circ}$ resolution. This product does not account for the modulations in the transmission of momentum from the atmosphere to the ocean related to seasonal or interannual changes in sea ice distribution. We focus here on the model dynamics, which are valid for any prescribed surface momentum forcing, and we discuss the implications of sea ice variability in section $6 \mathrm{~b}$. The time-mean zonal and meridional wind stress distributions as well as the time-mean wind stress curl are shown in Fig. 4. The wind stress curl is almost uniformly negative over the gyre and is particularly strong $(\sim 2 \times$ $10^{-7} \mathrm{~N} \mathrm{~m}^{-3}$ ) along the gyre boundary.

The components of the surface wind stress perpendicular to the 75 sections described in section $2 \mathrm{a}$ are averaged to produce the azimuthal-mean wind stress tangential to the gyre boundary. Figure $4 d$ shows the amplitude of each Fourier mode of the azimuthal-mean tangential wind stress at the shelf break $\tau(r=R, t)$, which is computed from the 58-yr CORE.v2 time series. Negative values correspond to cyclonic wind stress. With the exception of the steady mode, whose amplitude is $-0.073 \mathrm{~N} \mathrm{~m}^{-2}$, only the annual and semiannual modes are pronounced at the shelf break, having amplitudes of
-0.029 and $-0.011 \mathrm{Nm}^{-2}$, respectively. The estimated standard deviation of the Fourier modes plotted in Fig. $4 \mathrm{~d}$ is $0.0044 \mathrm{~N} \mathrm{~m}^{-2}$ for the annual mode and less than $0.0028 \mathrm{~N} \mathrm{~m}^{-2}$ for other modes. The relative amplitudes of the modes are similar at all radii from the gyre center. The contribution to isopycnal displacement from each mode follows the same physical processes, because our model is approximately linear with time, as shown in section 3 . Furthermore, the observed annual cycle of AABW in the northern Weddell Sea motivates this study. Therefore, for simplicity we include only the annual mode in our conceptual model and neglect all other modes. Numerical experiments show that the semiannual mode can modify isopycnal excursions at the gyre edge by $10 \%-20 \%$; this is discussed further in section 6 .

Figure $4 \mathrm{e}$ shows the radial variation in the amplitudes of the steady and annual azimuthal wind stress modes. Both modes strengthen linearly from the gyre interior to the gyre boundary. Thus, the steady and annual modes are represented by $\bar{\tau}(r)=\bar{\tau}^{0} r / R$ and $\tau_{12}(r)=$ $\tau_{12}^{0} r / R$, respectively, where $\bar{\tau}^{0}=-0.072 \mathrm{~N} \mathrm{~m}^{-2}$ and $\tau_{12}^{0}=$ $-0.026 \mathrm{~N} \mathrm{~m}^{-2}$ are constants. In a circular basin, the azimuthal wind stress must vanish at $r=0$ by symmetry. Figure $4 \mathrm{f}$ shows the radial variation of the phase $\phi_{12}$ of the annual mode, where the annual mode is expressed as $\tau_{12}(r) \sin \left[\omega t+\phi_{12}(r)\right]$ and $\omega=2 \pi \mathrm{yr}^{-1}$. The phase $\phi_{12}$ varies by less than $35^{\circ}$ for $r>100 \mathrm{~km}$, and for $r<100 \mathrm{~km}$ the amplitude of the annual mode is close to zero, so for simplicity we approximate $\phi_{12} \equiv 300^{\circ}$ as a constant. Thus, our expression for the azimuthal wind stress is

$$
\begin{aligned}
\tau(r, t) & =\bar{\tau}(r)+\tau_{12}(r) \sin (\omega t+5 \pi / 3), \quad \text { where } \\
\bar{\tau}(r) & =\bar{\tau}^{0} \frac{r}{R} \quad \text { and } \quad \tau_{12}(r)=\tau_{12}^{0} \frac{r}{R} .
\end{aligned}
$$

Here $t=0$ corresponds to the start of January, so the model wind field has an annual cycle with a maximum amplitude at $t=5$ months, that is, at the end of May. This wind pattern is consistent with previous observations [see, e.g., Fig. 1d of Wang et al. (2012)].

\section{Residual-mean dynamics}

We now derive an evolution equation for the bounding isopycnal $z=\eta(r, t)$ using RMT. Our formulation is similar to that of Marshall and Radko (2003), except it is cast in terms of an azimuthal average of the buoyancy around our idealized Weddell Gyre. Note that our model and its derivation in this section could be applied to any isopycnal in the Weddell Gyre.

Following Marshall and Radko (2003), the azimuthally averaged buoyancy may be written as 
(a)

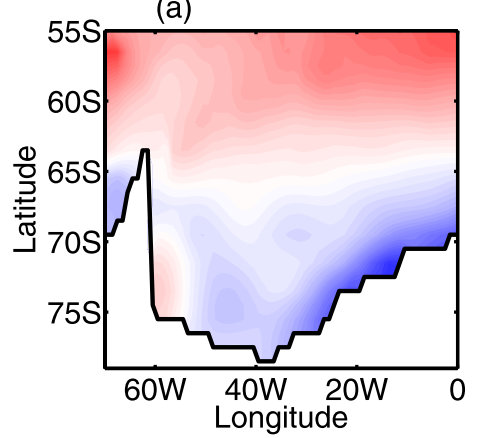

(d)

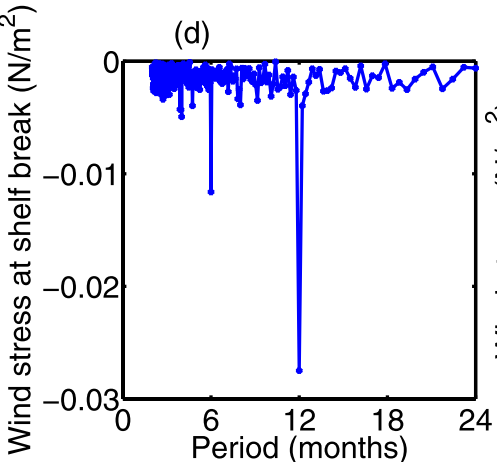

(b)

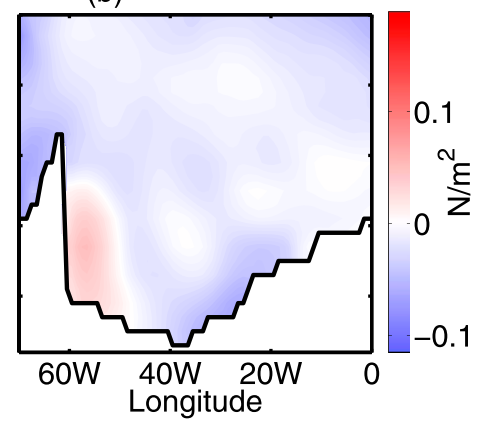

(e)

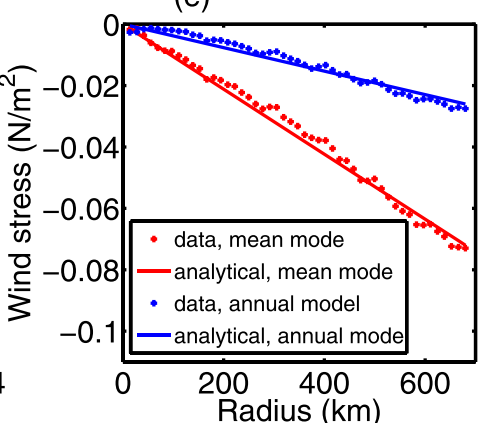

(c)

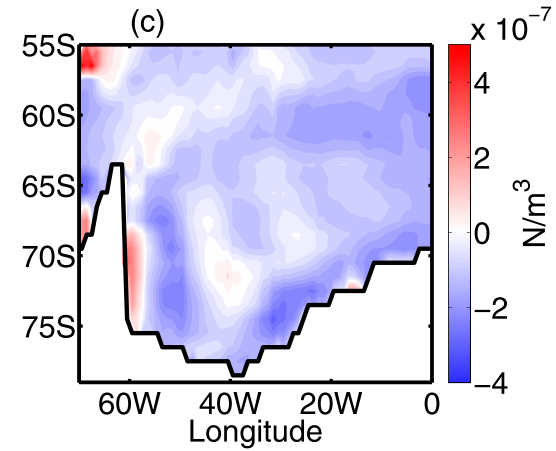

(f)

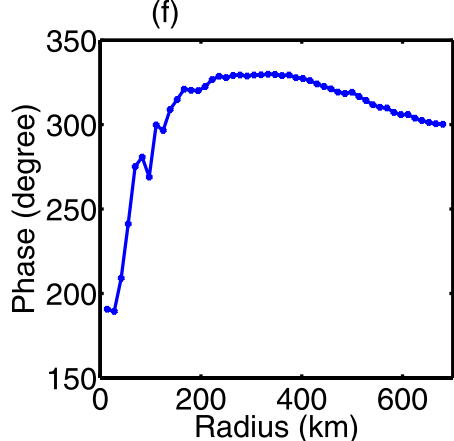

FIG. 4. Time-averaged (1949-2006) (a) zonal and (b) meridional wind stress components and (c) wind stress curl over the Weddell Sea and neighboring basins. (d) Amplitude of the Fourier modes (oscillation periods) for the azimuthal-mean tangential wind stress at the gyre boundary. Details of the calculation and the standard deviation of the amplitudes are described in section $2 \mathrm{~b}$. The amplitude of the timeindependent mode is $-0.073 \mathrm{~N} \mathrm{~m}^{-2}$ (not shown); negative amplitudes correspond to cyclonic winds. (e) Radial dependence of the steady and annual mode amplitudes, $\bar{\tau}$ and $\tau_{12}$, of the azimuthal-mean tangential wind stress. (f) Radial dependence of the phase $\phi_{12}$ of the annual mode of the azimuthal-mean tangential wind stress.

$$
\langle b\rangle_{t}+J\left(\psi^{\dagger},\langle b\rangle\right)=0
$$

where $b$ is the buoyancy, and angle brackets $\langle\cdot\rangle=$ $(2 \pi)^{-1} \oint \cdot d \theta$ denote the azimuthal average. The residual streamfunction $\psi^{\dagger}$ describes the advecting two-dimensional velocity field in the $(r, z)$ plane, defined as $\mathbf{u}^{\dagger}=u^{\dagger} \mathbf{e}_{r}+$ $w^{\dagger} \mathbf{e}_{z}=\boldsymbol{\nabla} \times\left(\psi^{\dagger} \mathbf{e}_{\theta}\right)$ with

$$
u^{\dagger}=-\frac{\partial \psi^{\dagger}}{\partial z} \quad \text { and } \quad w^{\dagger}=\frac{1}{r} \frac{\partial r \psi^{\dagger}}{\partial r}
$$

A turbulent diapycnal mixing term $\left(\kappa_{v}\langle b\rangle_{z}\right)_{z}$ has been neglected from the right-hand side of (3), where $\kappa_{v}$ is the vertical diffusivity. This term may be shown to be dynamically negligible in our model; this is discussed in detail in section $6 b$.

The residual streamfunction $\psi^{\dagger}$ is composed of a mean (wind driven) component $\langle\psi\rangle$ and an eddy component $\psi^{\star}$ :

$$
\psi^{\dagger}=\langle\psi\rangle+\psi^{\star}, \quad \text { where }\langle\psi\rangle=\frac{\tau}{\rho_{0} f_{0}} \quad \text { and } \quad \psi^{\star}=\kappa s_{b} .
$$

Following a procedure analogous to Marshall and Radko (2003), the mean streamfunction $\langle\psi\rangle$ is related to the surface wind stress using the azimuthally averaged azimuthal momentum equation in the limit of the small Rossby number. The same physical reasoning applies to both the ACC and the Weddell Gyre: in the zonal (azimuthal) mean the ACC (Weddell Gyre) cannot support a net zonal (azimuthal) pressure gradient, and thus no mean geostrophic meridional (radial) flow in the interior, so mean Ekman pumping driven by zonal (cyclonic) surface winds penetrates to depth. Here, $\rho_{0}$ is the reference density and $f_{0}$ is the reference Coriolis parameter. The latitudinal variation of the Coriolis parameter is about $5 \%$ in the Weddell Gyre and has been neglected here. The eddy streamfunction arises from a downgradient eddy buoyancy flux closure (Gent and McWilliams 1990), where $\kappa$ is the eddy buoyancy diffusivity and $s_{b}=-\langle b\rangle_{r} /\langle b\rangle_{z}$ is the isopycnal slope.

As the azimuthal-mean isopycnal $z=\eta(r, t)$ is a material surface in the sense of the residual advective derivative $D^{\dagger} / D_{t} \equiv \partial_{t}+\mathbf{u}^{\dagger} \cdot \nabla$, it may be shown (see appendix A) that it evolves according to

$\frac{\partial \eta(r, t)}{\partial t}=\frac{1}{r} \frac{\partial}{\partial r}\left[\left.r \psi^{\dagger}\right|_{z=\eta(r, t)}\right]$, where $0<r<r_{b}(t)$.

It is shown in (6) that the evolution of the isopycnal must be balanced by the radial divergence of $\psi^{\dagger}$, that is, the 
net radial transport between the isopycnal and the ocean bed. Inserting (5) into (6) and noting $s_{b}=\partial \eta / \partial r$, we obtain a forced-diffusive evolution equation for the isopycnal height $\eta$ :

$$
\frac{\partial \eta}{\partial t}=\frac{1}{r} \frac{\partial}{\partial r} r\left(\frac{\tau}{\rho_{0} f_{0}}+\kappa \frac{\partial \eta}{\partial r}\right)
$$

for $0<r<r_{b}(t)$. Here $\kappa=\kappa(r, t)$ is the eddy buoyancy diffusivity evaluated on the isopycnal $z=\eta(r, t)$, and the $\partial \eta / \partial r$ is isopycnal slope. We impose no flux boundary conditions $\left(\psi^{\dagger}=0\right)$ at the gyre center $r=0$ and at the isopycnal outcrop $r=r_{b}(t)$.

The azimuthally averaged wind stress $\tau$ must vanish at $r=0$ by symmetry, so from (5) the boundary condition is

$$
\left.\psi^{\dagger}\right|_{r=0}=\left.0 \Rightarrow \frac{\partial \eta}{\partial r}\right|_{r=0}=0 .
$$

Similarly, at the isopycnal outcrop $r=r_{b}(t)$ we obtain

$$
\left.\psi^{\dagger}\right|_{r=r_{b}}=\left.0 \Rightarrow \frac{\partial \eta}{\partial r}\right|_{r=r_{b}}=-\left.\frac{\tau}{\rho_{0} f_{0} \kappa}\right|_{r=r_{b}} .
$$

The outcrop position $r=r_{b}(t)$ evolves with time to satisfy $\eta\left[r_{b}(t), t\right]=\eta_{b}\left[r_{b}(t)\right]$. In numerical solutions of (7)-(8b), this evolution must be computed explicitly, as discussed in appendix B.

As we have not prescribed any inflow or outflow of WSDW at this point, our model conserves the total mass $M$ beneath the isopycnal $z=\eta(r, t)$ as follows:

$$
\frac{d M}{d t}=0 \quad \text { and } \quad M=\int_{0}^{r_{b}(t)} 2 \pi r \rho_{0}\left(\eta-\eta_{b}\right) d r .
$$

\section{The model solution}

\section{a. Analytical solution in cylindrical basin}

In this section, we solve the model evolution equation (7) analytically in a simplified case. The solution serves as a scaling for the isopycnal's response to the annually varying surface wind stress and provides an intuitive interpretation of our later results. For convenience, we choose the isopycnal separating CDW from WSDW, that is, $\gamma^{n}=28.26 \mathrm{~kg} \mathrm{~m}^{-3}$, for all the following discussions. The results translate to other isopycnals with the caveat that nonlinearities, such as diapycnal mixing, have been neglected in this model (see further discussion in section $6 \mathrm{~b}$ ).

Figure 1c shows that the WSDW isopycnal outcrops at the steepest part of the bathymetric slope. Our numerical solutions in section $4 \mathrm{~b}$ show that the change in $r_{b}$ related to isopycnal excursions is typically small $(<4 \mathrm{~km})$ because the bathymetric slope is steep here. We therefore approximate the basin as a cylinder with vertical walls at $r_{b} \equiv R=680 \mathrm{~km}$. We choose $\kappa=$ constant $=300 \mathrm{~m}^{2} \mathrm{~s}^{-1}$; this yields a range of isopycnal heights that approximately matches the observed range in Fig. 1c. In section 4c, we examine the model's sensitivity to the value of $\kappa$.

To solve the isopycnal evolution equation (7), we separate $\eta$ and $\tau$ into time-mean components $\bar{\eta}$ and $\bar{\tau}$ and time-dependent components $\eta^{\prime}$ and $\tau^{\prime}$, that is, $\eta=\bar{\eta}+\eta^{\prime}$ and $\tau=\bar{\tau}+\tau^{\prime}$. Taking the time average of (7) yields

$$
\frac{1}{r} \frac{\partial}{\partial r} r\left(\frac{\bar{\tau}}{\rho_{0} f_{0}}+\kappa \frac{\partial \bar{\eta}}{\partial r}\right)=0,
$$

where $\bar{\tau}=\bar{\tau}^{0} r / R$ from (2a). This equation defines the time-mean isopycnal position up to a constant, which we choose to be the basin-averaged isopycnal depth $\eta_{0}=$ $2 \int_{0}^{R} \eta r d r / R^{2}$. Solving (10), we obtain the time-mean isopycnal profile:

$$
\bar{\eta}(r)=\eta_{0}+\frac{\bar{\tau}^{0}}{4 \rho_{0} f_{0} \kappa R}\left(R^{2}-2 r^{2}\right) .
$$

The change in isopycnal height $\Delta \bar{\eta}=\bar{\eta}(r=0)-\bar{\eta}(r=R)=$ $\bar{\tau}^{0} R /\left(2 \rho_{0} f_{0} \kappa\right)$ depends on the amplitude of the mean wind stress component $\bar{\tau}^{0}$ and the eddy diffusivity $\kappa$. Physically, the time-mean isopycnal shape ensures that the time-mean, wind-driven, and eddy vertical velocities exactly cancel. For $\rho_{0}=1000 \mathrm{~kg} \mathrm{~m}^{-3}$ and $f_{0}=-10^{-4} \mathrm{~s}^{-1}$, we obtain $\Delta \bar{\eta}=860 \mathrm{~m}$, which is consistent with the observed range of $\sim 800 \mathrm{~m}$ shown in Fig. 1c. The analytical profile (11) for $\bar{\eta}$ is shown in Fig. 5a and agrees almost exactly with the numerical solution in a curved basin (see section $4 b)$. The isopycnal tilt $\partial \bar{\eta} / \partial r$ is enhanced close to the gyre boundary, consistent with Fig. 1c.

Subtracting the evolution equation (7) from its time mean (10) yields an equation for the time-dependent component of $\eta$ :

$$
\frac{\partial \eta^{\prime}}{\partial t}=\frac{1}{r} \frac{\partial}{\partial r} r\left(\frac{\tau^{\prime}}{\rho_{0} f_{0}}+\kappa \frac{\partial \eta^{\prime}}{\partial r}\right) .
$$

From (2a) the time-dependent wind stress component is $\tau^{\prime}=\operatorname{Re}\left[-i e^{i(\omega t+5 \pi / 3)} \tau_{12}(r)\right]$, where $\operatorname{Re}$ indicates the real part of the term in brackets, so we seek a solution of the form $\eta^{\prime}=\operatorname{Re}\left[-i e^{i(\omega t+5 \pi / 3)} \hat{\eta}(r)\right]$. Then (12) reduces to an ordinary differential equation for the radial structure function $\hat{\eta}$ :

$$
\frac{d^{2} \hat{\eta}}{d r^{2}}+\frac{1}{r} \frac{d \hat{\eta}}{d r}-\frac{i \omega}{\kappa} \hat{\eta}=-\frac{2 \tau_{12}^{0}}{\rho_{0} f_{0} \kappa R}
$$


(a)

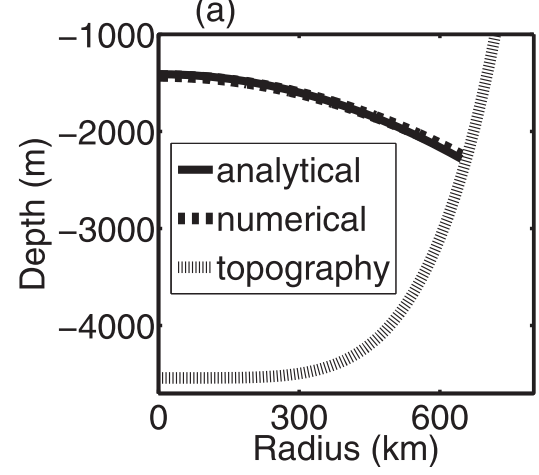

(b)

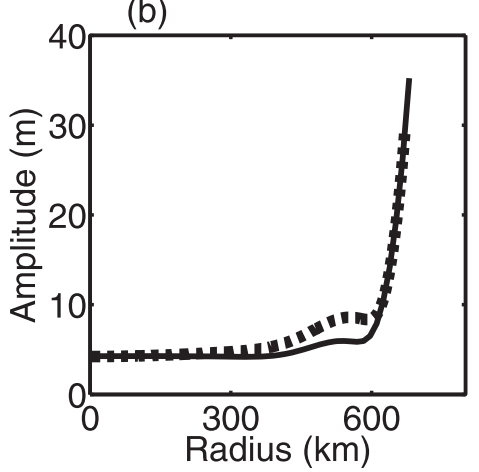

(c)

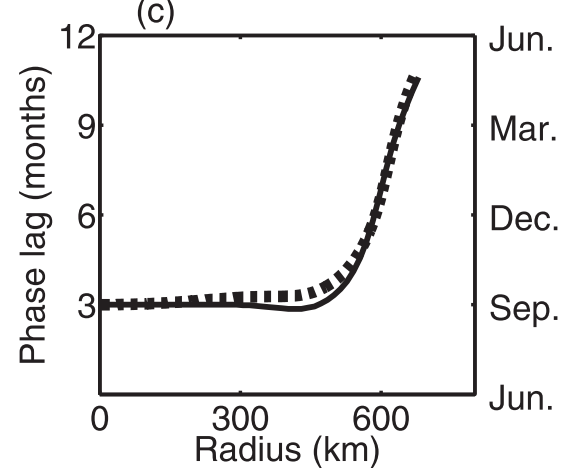

FIG. 5. Analytical solution in a cylindrical basin (solid) and numerical solution in a curved basin (dashed) with no inflow/outflow of WSDW. (a) The time-mean isopycnal height $\bar{\eta}(r)$. (b) Amplitude of the isopycnal oscillation $\left|\eta^{\prime}\right|$. (c) Phase lag of oscillation $\eta^{\prime}$, defined as the time interval from the wind stress max to the isopycnal height max. The wind stress max occurs at the beginning of June each year.

while the boundary condition ( $8 \mathrm{~b})$ becomes

$$
\left.\frac{\partial \hat{\eta}}{\partial r}\right|_{r=R}=-\frac{\tau_{12}^{0}}{\rho_{0} f_{0} \kappa}
$$

Note that the right-hand side of (13) is a constant. The solution to (13) is

$$
\hat{\eta}(r)=(1+i) \frac{\tau_{12}^{0}}{\rho_{0} f_{0} \sqrt{2 \omega \kappa}} \frac{J_{0}\left[\sqrt{\frac{\omega}{2 \kappa}}(1-i) r\right]}{J_{1}\left[\sqrt{\frac{\omega}{2 \kappa}}(1-i) R\right]}-i \frac{2 \tau_{12}^{0}}{\rho_{0} f_{0} \omega R},
$$

where $J_{0}$ and $J_{1}$ are the Bessel functions of the zeroth and first kinds, respectively.

Equation (15) tells us that the isopycnal oscillates annually about its time-mean position $\bar{\eta}$ with radially varying amplitude and phase. In Figs. $5 b$ and $5 c$, we plot the oscillation amplitude and phase lag of $\eta^{\prime}(r, t)$, where the phase lag is defined as the number of months by which the isopycnal height maximum lags the wind stress maximum at each point. The analytical result compares well with our numerical solution, which uses the curved bathymetry shown in Fig. 5a.

Figure 5 shows that the character of the isopycnal oscillation undergoes a pronounced change close to the gyre boundary. This is due to the formation of a boundary layer close to $r=R$, in which mesoscale eddy diffusion dominates the evolution of $\eta$. The time scale associated with eddy diffusion may be estimated from (12) as $T_{\text {eddy }}=R^{2} / \kappa \sim 50 \mathrm{yr}$, much longer than the $1 \mathrm{yr}$ time scale of the wind stress variations. Defining an asymptotically large parameter, $\epsilon^{-1}=\omega R^{2} / \kappa \gg 1$, it follows from the large argument asymptotic form of the Bessel function (Abramowitz and Stegun 1965) that as $\epsilon \rightarrow 0$,

$$
\eta^{\prime} \sim-\frac{2 \tau_{12}^{0}}{\rho_{0} f_{0} \omega R} \cos \left(\omega t+\frac{5 \pi}{3}\right) \quad \text { for } \quad r / R=\mathcal{O}(1) \quad \text { and }
$$

$$
\eta^{\prime} \sim \frac{\tau_{12}^{0}}{\rho_{0} f_{0} \sqrt{\omega \kappa}} \sin \left(\omega t-\frac{\pi}{12}\right) \quad \text { for } \quad r / R=1-\mathcal{O}\left(\epsilon^{1 / 2}\right) .
$$

Thus, in the gyre interior $[r / R=\mathcal{O}(1)]$, the evolution of $\eta^{\prime}$ in (12) is dominated by the wind-driven vertical velocity. This results in a small oscillation with the amplitude $2 \tau_{12}^{0} /\left(\rho_{0} f_{0} \omega R\right) \approx 4.3 \mathrm{~m}$. The isopycnal oscillation lags the wind stress maximum, or equivalently the wind-driven vertical velocity maximum, by 3 months, achieving its maximum in September each year (Fig. 5c).

Close to the gyre edge, a boundary layer forms in which eddies dominate the isopycnal oscillation $[r / R=$ $\left.1-\mathcal{O}\left(\epsilon^{1 / 2}\right)\right]$. The width of this layer may be estimated as $L_{\text {eddy }}=\epsilon^{1 / 2} R \sim 40 \mathrm{~km}$. The amplitude of the oscillation in the boundary layer is an order of magnitude greater than in the interior, reaching $\tau_{12}^{0} /\left(\rho_{0} f_{0} \sqrt{\omega \kappa}\right) \approx 37.5 \mathrm{~m}$ at the edge of the gyre. This scaling shows that the oscillation amplitude is sensitive to both the wind stress $\tau_{12}^{0}$ and the eddy diffusivity $\kappa$. We examine the sensitivity of the model to these parameters in section $4 \mathrm{c}$. At the gyre boundary, the isopycnal height maximum (minimum) lags the wind stress maximum by 11 (5) months. This phase corresponds closely to observations of WSDW at the Orkney Passage and is discussed further in section 6a.

\section{b. Numerical solutions in a curved basin}

For the curved bathymetry shown in Fig. 3, or for spatially varying eddy diffusivity $\kappa$, the evolution equation (7) is no longer analytically tractable. To study these more complicated cases we solve the model equations 
(a)

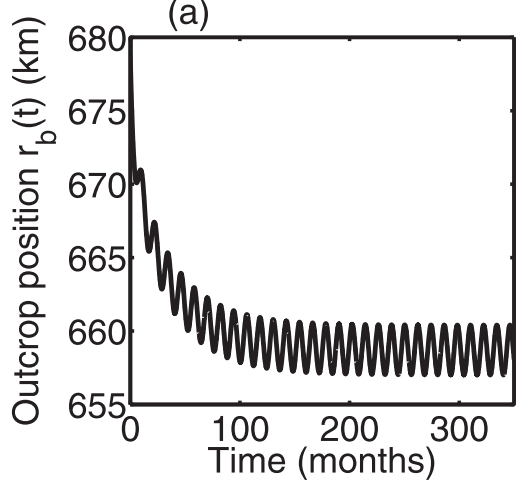

(b)

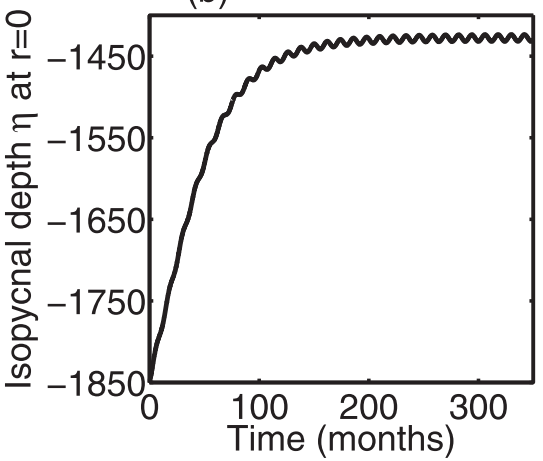

(c)

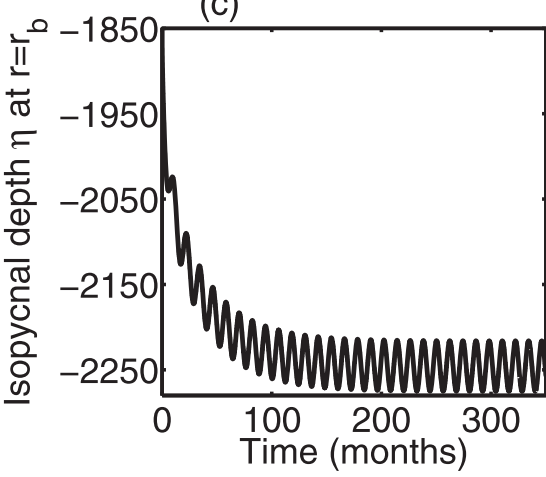

FIG. 6. Evolution of the reference solution $\left(\tau_{12}^{0}=0.026 \mathrm{~N} \mathrm{~m}^{-2}, \kappa=300 \mathrm{~m}^{2} \mathrm{~s}^{-1}\right)$, obtained numerically as discussed in section $4 \mathrm{~b}$. (a) Outcrop position $r=r_{b}(t)$ and isopycnal height evolution at (b) the gyre center and (c) at the boundary outcrop.

(7)-(8b) numerically. Our numerical scheme is described in appendix B.

Figure 5 compares our numerical and analytical solutions using the same parameters, except our numerical solution uses the idealized bathymetry shown in Fig. 3. The time-mean isopycnal heights are almost identical, and there is only a slight discrepancy in the amplitude and phase of the oscillation due to the bathymetry. In particular, a boundary layer of the same width develops in both the numerical and analytical solutions, yielding similar predictions for the properties of the isopycnal oscillation at the gyre edge where WSDW escapes via the Orkney Passage.

Figure 6 shows plots of the time evolution of the numerical solution. The initial condition for the isopycnal is $\eta(r, 0) \equiv \eta_{0}=$ constant, where $\eta_{0}$ is the basin-averaged isopycnal height as in section 4a. Wind-driven upwelling causes the WSDW isopycnal to dome up (see Fig. 5a), resulting in the outcrop position $r_{b}(t)$ contracting from 680 to $658 \mathrm{~km}$. The outcrop then oscillates about this position with an amplitude of around $2 \mathrm{~km}$. This small oscillation amplitude is due to the sharp basin slope $d \eta_{b} /$ $d r$ at the gyre edge and justifies our treatment of $r_{b}$ as a constant in section $4 a$. Figures $6 \mathrm{~b}$ and $6 \mathrm{c}$ show the evolution of the isopycnal height at the gyre center $\eta(r=$ $0, t)$ and at the outcrop $\eta\left(r=r_{b}, t\right)$. They approach a sinusoidal annual oscillation with amplitudes of around 4 and $30 \mathrm{~m}$, respectively, consistent with our analytical scalings in section $4 a$.

\section{c. Sensitivity to wind stress and eddy diffusivity}

In this section, we examine the sensitivity of the analytical and numerical solutions discussed in sections $4 \mathrm{a}$ and $4 \mathrm{~b}$ to the surface wind stress and the eddy diffusivity.

In section $2 \mathrm{~b}$, the azimuthally averaged surface wind stress $\tau(r, t)$ was derived from reanalysis data (Large and Yeager 2009). This product is poorly constrained at high latitudes, so in Figs. 7a-c we plot properties of our model solution for annual wind stress mode amplitudes $\tau_{12}^{0}$ in the range of $0.02-0.05 \mathrm{~N} \mathrm{~m}^{-2}$. Here, $\kappa$ is fixed at $300 \mathrm{~m}^{2} \mathrm{~s}^{-1}$. Figures $7 \mathrm{a}$ and $7 \mathrm{c}$ show that $\tau_{12}^{0}$ has no impact on the time-mean isopycnal profile nor the phase of the isopycnal oscillation, while Figs. $7 \mathrm{~b}$ and $7 \mathrm{~d}$ indicate that the amplitude of the oscillation varies linearly with $\tau_{12}^{0}$. These are both consistent with our analytical scaling in section $4 \mathrm{a}$. The isopycnal oscillation amplitude reaches $50 \mathrm{~m}$ at the boundary for an annual wind stress mode amplitude of $\tau_{12}^{0}=0.05 \mathrm{~N} \mathrm{~m}^{-2}$.

Direct observations of eddy diffusivities $\kappa$ in the Weddell Sea or other Antarctic coastal regions are limited. Therefore, the eddy diffusivity applied in sections $4 \mathrm{a}$ and $4 \mathrm{~b}$ was selected to ensure that the time-mean isopycnal height profile matched that shown in Fig. 1c. As a basic sensitivity study, we assume that $\kappa$ is homogeneous everywhere. In Figs. 7e-g, we plot properties of our model solution for $\kappa$ in the range $200-600 \mathrm{~m}^{2} \mathrm{~s}^{-1}$. This range was chosen so that the change in the time-mean isopycnal height across the basin $\Delta \bar{\eta}$ remains within a few hundred meters of the observed $\Delta \bar{\eta} \sim 800 \mathrm{~m}$. We fix $\tau_{12}^{0}=$ $0.026 \mathrm{~N} \mathrm{~m}^{-2}$ in all cases. Figure $7 \mathrm{e}$ shows that the timemean isopycnal height $z=\bar{\eta}(r)$ is sensitive to $\kappa$, consistent with the analytical prediction that the isopycnal vertical range satisfies $\Delta \bar{\eta} \propto \kappa^{-1}$ from (11). Figures 7f and 7g show that the phase of the oscillation and its amplitude in the gyre interior are relatively insensitive to $\kappa$, while Figs. $7 f$ and $7 \mathrm{~h}$ show that the amplitude at the gyre edge can have a significant dependence on $\kappa$. This is consistent with our analytical scaling $\left|\eta^{\prime}\right| \sim \kappa^{-1 / 2}$ for the oscillation amplitude at the gyre edge.

\section{d. Eddy suppression by the bathymetric slope}

In general, the oceanic eddy buoyancy diffusivity $\kappa$ exhibits strong spatial inhomogeneity, both laterally and vertically (Abernathey et al. 2010; Abernathey and 
(a)

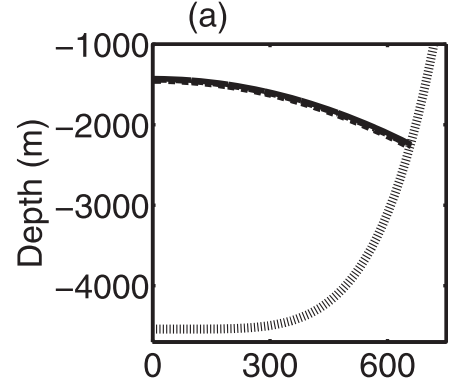

(e)

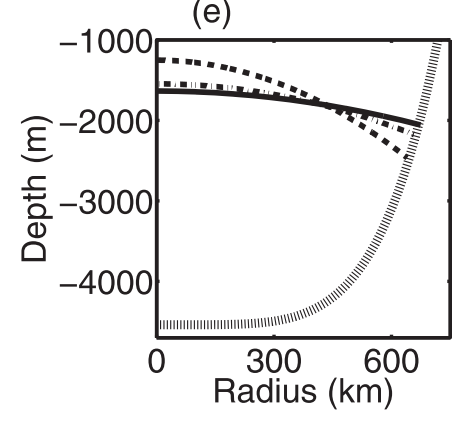

(b)

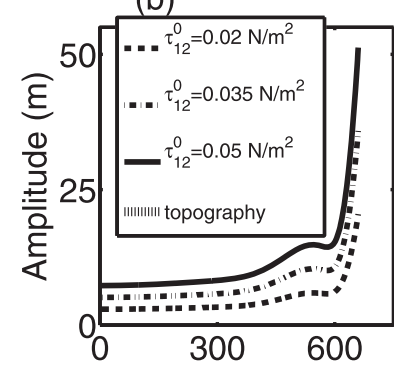

(f)

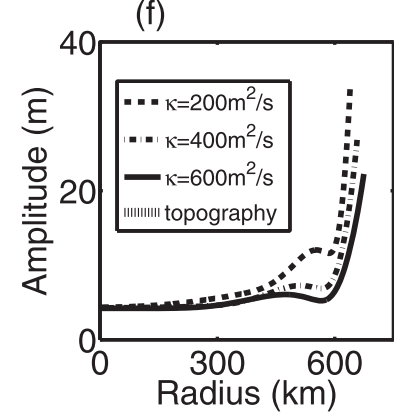

(c)

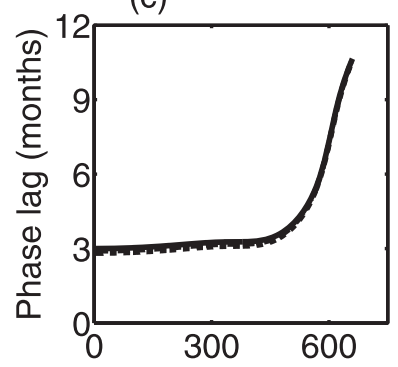

(g)

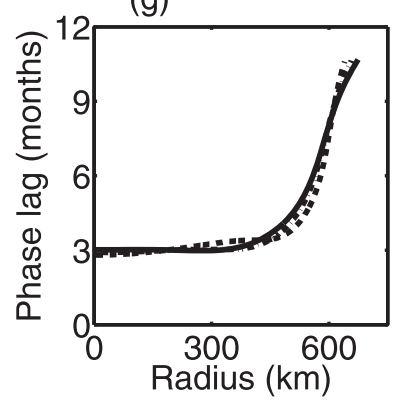

(d)

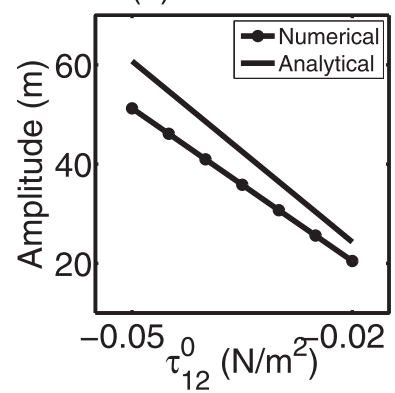

(h)

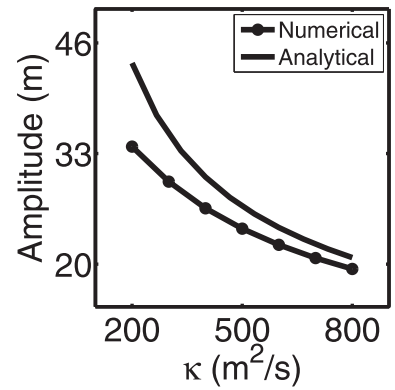

FIG. 7. (top) Sensitivity of our model solution to the wind stress $\tau_{12}^{0}$, with fixed $\kappa=300 \mathrm{~m}^{2} \mathrm{~s}^{-1}$. (bottom) Sensitivity to the eddy diffusivity $\kappa$, with fixed $\tau_{12}^{0}=0.026 \mathrm{~N} \mathrm{~m}^{-2}$. (a), (e) The time-mean isopycnal height $\bar{\eta}$. (b),(f) Amplitude of the isopycnal oscillation $\left|\eta^{\prime}\right|$. (c),(g) Phase lag of the isopycnal oscillation $\eta^{\prime}$, defined as the time interval from the wind stress max to the isopycnal height max. (d) Oscillation amplitude at the isopycnal outcrop for a range of wind stress strengths $\tau_{12}^{0}$. (h) Oscillation amplitude at the isopycnal outcrop for a range of eddy diffusivities $\kappa$. The legend in (b) applies to (a)-(c) and the legend in (f) applies to (e)-(g). These solutions were computed numerically as described in section $4 \mathrm{~b}$.

Marshall 2013). In particular, numerical simulations and laboratory experiments show that $\kappa$ can be reduced by from one to two orders of magnitude over steep continental slopes (Isachsen 2011; Pennel et al. 2012; Stewart and Thompson 2013). Here, we attempt to determine the effect that such eddy suppression might have on the annual isopycnal oscillation using a parameterization of $\kappa$ based on linear two-layer quasigeostrophic baroclinic instability theory (e.g., Mechoso 1980; Pennel et al. 2012).

From linear two-layer quasigeostrophic baroclinic instability theory (Stone 1972; Pedlosky 1987), we parameterize the eddy diffusivity using the growth rates of the Phillips problem over a sloping bottom:

$$
\kappa=c \sigma \lambda^{2} .
$$

Here $\sigma$ is the maximum growth rate of baroclinic instability, and $\lambda$ is the wavelength of the most unstable mode. The parameter $c$ is a dimensionless constant and its value is chosen so that the change in the time-mean isopycnal height across the gyre approximately matches the observed value of $\sim 800 \mathrm{~m}$. In the Phillips problem, the growth rate depends upon the isopycnal slope $s_{\rho}=$ $d \eta / d r$, the bathymetric slope $s_{b}=d \eta_{b} / d r$, the thickness of the overlying CDW layer $h_{\mathrm{CDW}}$, the thickness of the WSDW layer $h_{\mathrm{WSDW}}$, and the reduced gravity $g^{\prime}$ for the two-layer system (prescribed as $5 \times 10^{-4} \mathrm{~m} \mathrm{~s}^{-2}$ ). This parameterization assumes that eddy mixing of buoyancy responds instantaneously to changes in the isopycnal slope. In reality, the instability must grow to the point that baroclinic eddies form and mix along isopycnals.

Using parameterization (17) with $c=50$, Fig. 8d shows the time-mean profile of $\kappa$ as the isopycnal evolves in our model. Note that $\kappa$ evolves on seasonal time scales in response to changes in isopycnal slope and layer depths. Close to the isopycnal outcrop $\left(h_{\mathrm{CDW}} /\right.$ $\left.h_{\mathrm{WSDW}} \ll 1\right)$, the bathymetry is much steeper than the isopycnal slope $\left(\left|s_{b} / s_{\rho}\right| \gg 1\right)$, so the eddy diffusivity is suppressed due to the weaker baroclinic instability (Isachsen 2011). Close to the gyre center the isopycnal must flatten by (8a), so the eddy diffusivity is also suppressed. Thus, $\kappa$ reaches its maximum at midradius. The suppression of $\kappa$ close to the outcrop requires the isopycnal to steepen locally so that the mean and eddy streamfunctions in (5) balance in the time mean. This shape more closely resembles the observed isopycnal structure in Fig. 1c than the case with uniform $\kappa$.

In Fig. 8, we plot the properties of the model solution for $c$ in the range 10-100. As in the case of uniform $\kappa$, the 
(a)

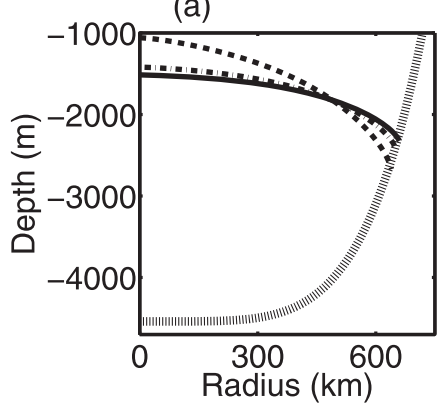

(b)

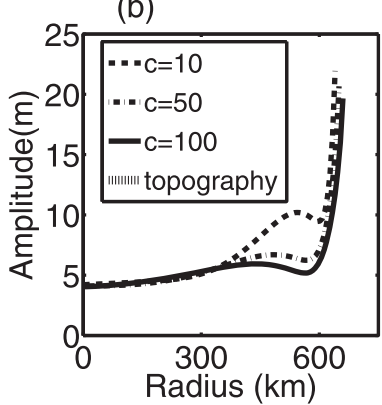

(c)

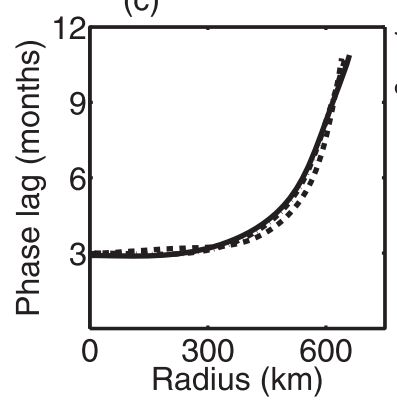

(d)

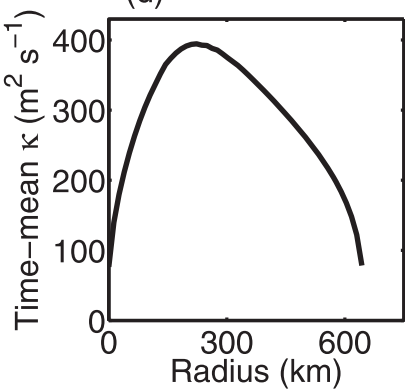

FIG. 8. (a)-(c) As in Fig. 5, but for an eddy diffusivity $\kappa$ constructed via (17) from linear two-layer quasigeostrophic baroclinic instability theory. When the constant $c$ in (17) equals 10,50 , and 100 , the corresponding domain-average $\kappa$ is about 100,300 , and $450 \mathrm{~m}^{2} \mathrm{~s}^{-1}$, respectively. (d) The time-mean profile of $\kappa$ using $c=50$ as the isopycnal evolves in our model.

time-mean isopycnal height is sensitive to $c$. A weaker eddy diffusivity requires a larger isopycnal slope to produce the downward eddy vertical velocity necessary to balance the time-mean wind-driven upwelling. The oscillation phase is insensitive to $c$ as in the case of uniform $\kappa$. Surprisingly, the oscillation amplitude at the isopycnal outcrop (Fig. $8 b$ ) is much less sensitive to $c$ than in the uniform $\kappa$ case, which seems inconsistent with our analytical scaling in section $4 \mathrm{a}$. This is due to the large radial gradient of $\kappa$, which enters as a term of the form $(1 / r) \cdot \partial \kappa / \partial r \cdot \partial(r \eta) / \partial r$ in (7) and is neglected in our analytical solution in section $4 \mathrm{a}$. We find the ratio of the diffusive terms in (7) is large, that is, $\left|\left(\kappa_{r} \eta_{r}^{\prime}\right) /\left(\kappa \eta_{r r}^{\prime}\right)\right| \gg 1$, close to the gyre boundary.

\section{The impact of inflow/outflow of WSDW}

In this section, we address the impact of an inflow/ outflow of WSDW on the annual oscillation of the isopycnals in the Weddell Gyre. Our conceptual model is not capable of describing the full three-dimensional process of WSDW formation and export, so here we develop an azimuthally averaged representation of the inflow to and outflow from the WSDW layer.

\section{a. Parameterizing inflow/outflow of WSDW}

For simplicity, we assume that the isopycnal $z=\eta(r, t)$ divides the water masses of the gyre into two homogeneous layers: an upper layer of CDW and a lower layer of WSDW. The primary source of WSDW is a mixture of dense shelf water (glacial meltwater and a high salinity shelf water caused by sea ice formation) with entrained CDW (Orsi and Wiederwohl 2009). We parameterize production as a total transport $T_{i}$ into the WSDW layer. Geostrophic estimates indicate that around $6 \mathrm{~Sv}$ of WSDW escapes the Weddell Gyre through the Orkney Passage (Naveira Garabato et al. 2002), which is calculated by computing the geostrophic shear and estimating the barotropic component of the flow from the LADCP data. We include in our model only the component of WSDW that escapes via the Orkney Passage, so a typical strength for $T_{i}$ is $6 \mathrm{~Sv}$. Simulations by Kida (2011) and Wang et al. (2012) show that the WSDW inflow from the Filchner Depression often increases substantially with the surface wind stress because the inflow is geostrophically controlled. We parameterize the seasonal cycle in the inflow of WSDW as

$$
T_{i}(t)=T_{i}^{0}+\Gamma \sin [\omega(t-\alpha)+5 \pi / 3],
$$

where $T_{i}^{0}=6 \mathrm{~Sv}, \alpha$ is the phase lag from the wind stress maximum, and $\Gamma$ is the inflow oscillation amplitude. Wang et al. (2012) found a 4-month lag between the wind stress maximum and WSDW inflow maximum, so we use $\alpha=4$ months as a reference value. There is no available estimate of the amplitude $\Gamma$, so we choose $\Gamma=$ $4 \mathrm{~Sv}$ as a reference value.

The outflow of WSDW depends upon the thickness of the WSDW layer at the gyre edge, where the azimuthal flow encounters the Orkney Passage in the South Scotia Ridge. As illustrated in Fig. 2, we assume that the WSDW outflows through a cross-sectional area perpendicular to the edge of our circular gyre. The depth of the Orkney Passage is around $3 \mathrm{~km}$, so we assume that WSDW outflows at all radii greater than $r=r_{\mathrm{OP}}=550 \mathrm{~km}$, where the water column depth is roughly $3 \mathrm{~km}$. The total outflow transport is therefore

$$
T_{o}=\int_{r_{\mathrm{OP}}}^{r_{b}(t)}\left(\eta-\eta_{b}\right)(-v) d r
$$

where $v<0$ represents a cyclonic velocity.

To parameterize the azimuthal velocity $v$, we assume that the weak stratification in the Weddell Gyre leads to a predominantly barotropic boundary current. This agrees with Naveira Garabato et al. (2002) and Thompson and Heywood (2008), who observed barotropic currents on 
(a)

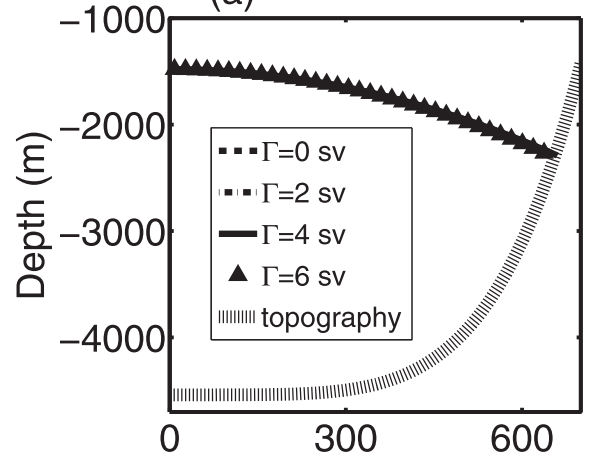

(d)

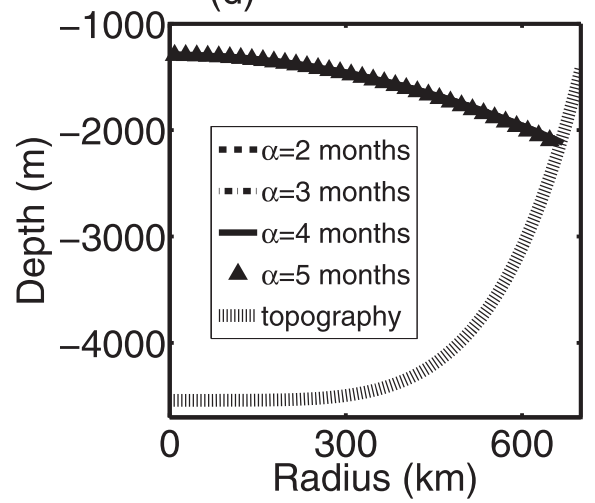

(b)

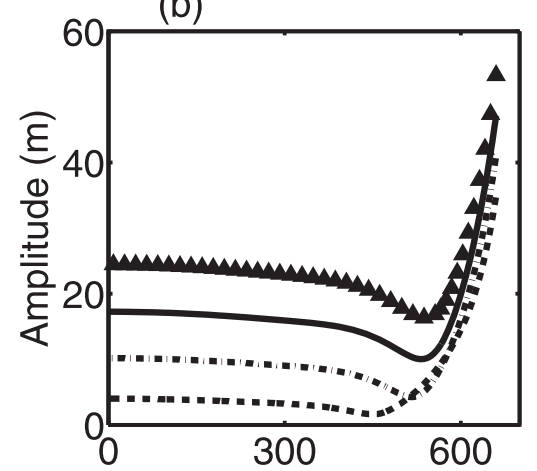

(e)

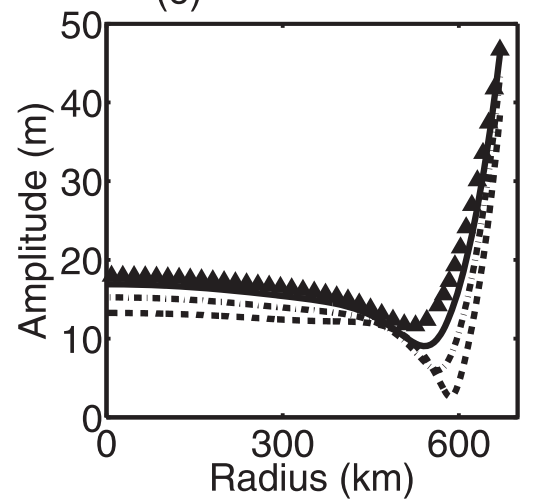

(c)

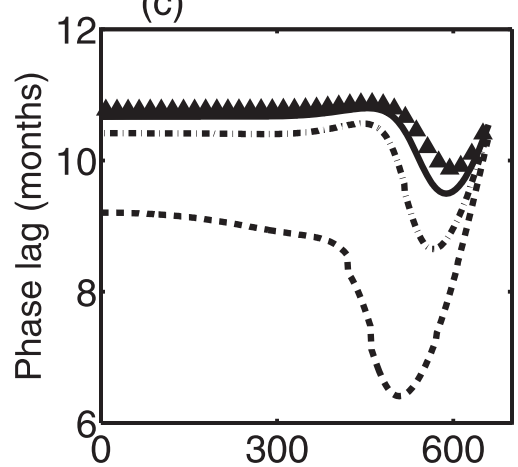

(f)

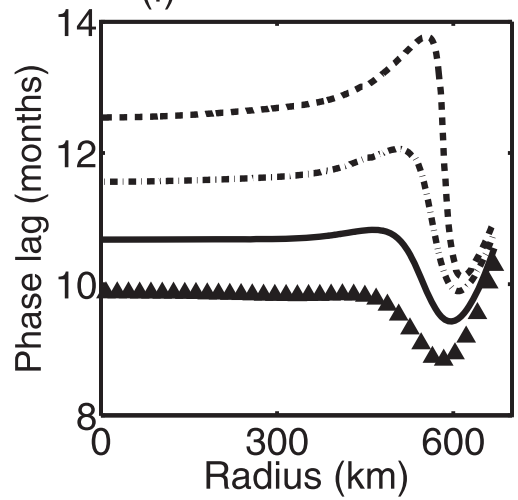

FIG. 9. Properties of the model solution with inflow and outflow of WSDW, as discussed in section 5. (a)-(c) As in Fig. 5, but for a range of inflow transport oscillation amplitudes $\Gamma$, with $\alpha=4$ months. (d)-(f) As in Fig. 5, but for a range of phase lags $\alpha$ between the wind stress max and the inflow transport max, with $\Gamma=4$ Sv. The legend in (a) applies to (a)-(c) and the legend in (d) applies to (d)-(f).

the northern and northwestern side of the Weddell Gyre, respectively. Assuming that the strength of this boundary current adjusts instantaneously to the southward Sverdrup transport in the gyre interior, and that its width remains constant, its velocity must be proportional to the wind stress at the gyre edge:

$$
v=v^{0}\left[1+\frac{\tau_{12}(R, t)}{\bar{\tau}(R)}\right],
$$

where the mean boundary current velocity $v^{0}=-6 \mathrm{~cm} \mathrm{~s}^{-1}$ has been selected based on observations (Naveira Garabato et al. 2002). This parameterization is discussed in detail in appendix $\mathrm{C}$. The annual variability of $T_{o}$ in (19) is about $3 \mathrm{~Sv}$, mainly due to the variations of the outflow velocity $v$ by around $50 \%$ over an annual cycle, whereas the WSDW layer thickness $\left(\eta-\eta_{b}\right)$ varies by roughly $10 \%$.

Finally, the inflow $T_{i}$ and outflow $T_{o}$ must be distributed across our idealized Weddell Gyre. Here, we consider only the simplest case in which both the inflow and outflow are evenly spread over the area $\pi r_{b}^{2}$ spanned by the isopycnal $z=\eta(r, t)$. We therefore include them in the isopycnal evolution equation (7) as follows:

$$
\frac{\partial \eta}{\partial t}=\frac{1}{r} \frac{\partial}{\partial r} r\left(\frac{\tau}{\rho_{0} f_{0}}+\kappa \frac{\partial \eta}{\partial r}\right)+\frac{T_{i}-T_{o}}{\pi r_{b}^{2}}
$$

Thus (21), (8a), and (8b) constitute our residual-mean model for the Weddell Gyre with WSDW inflow/outflow.

\section{b. Impact of WSDW inflow/outflow on the isopycnal oscillation}

We solve the extended isopycnal evolution equation (21) numerically using a straightforward extension of the numerical scheme described in appendix B. In Fig. 9 we plot the time-mean isopycnal profile, oscillation amplitude, and phase lag for a range of $\Gamma$ and $\alpha$. Figures $9 a-c$ show the sensitivity of $\eta$ to $\Gamma$ with $\alpha=4$ months, while Figs. 9d-f show the sensitivity from $\eta$ to $\alpha$ with $\Gamma=4$ Sv.

The case $\Gamma=0 \mathrm{~Sv}$ in Figs. 9a-c corresponds to a constant inflow of $T_{i}=6 \mathrm{~Sv}$, so the WSDW inflow does not affect the phase and amplitude of the oscillation in this case. The azimuthal velocity $v$ is proportional to the wind stress maximum, by (20), so in the gyre interior the isopycnal displacements caused by the WSDW outflow and the wind-induced vertical velocities are always opposed to one another. The oscillation induced by the outflow has an amplitude of $7.3 \mathrm{~m}$ as compared to a $4.3-\mathrm{m}$ 
(a)
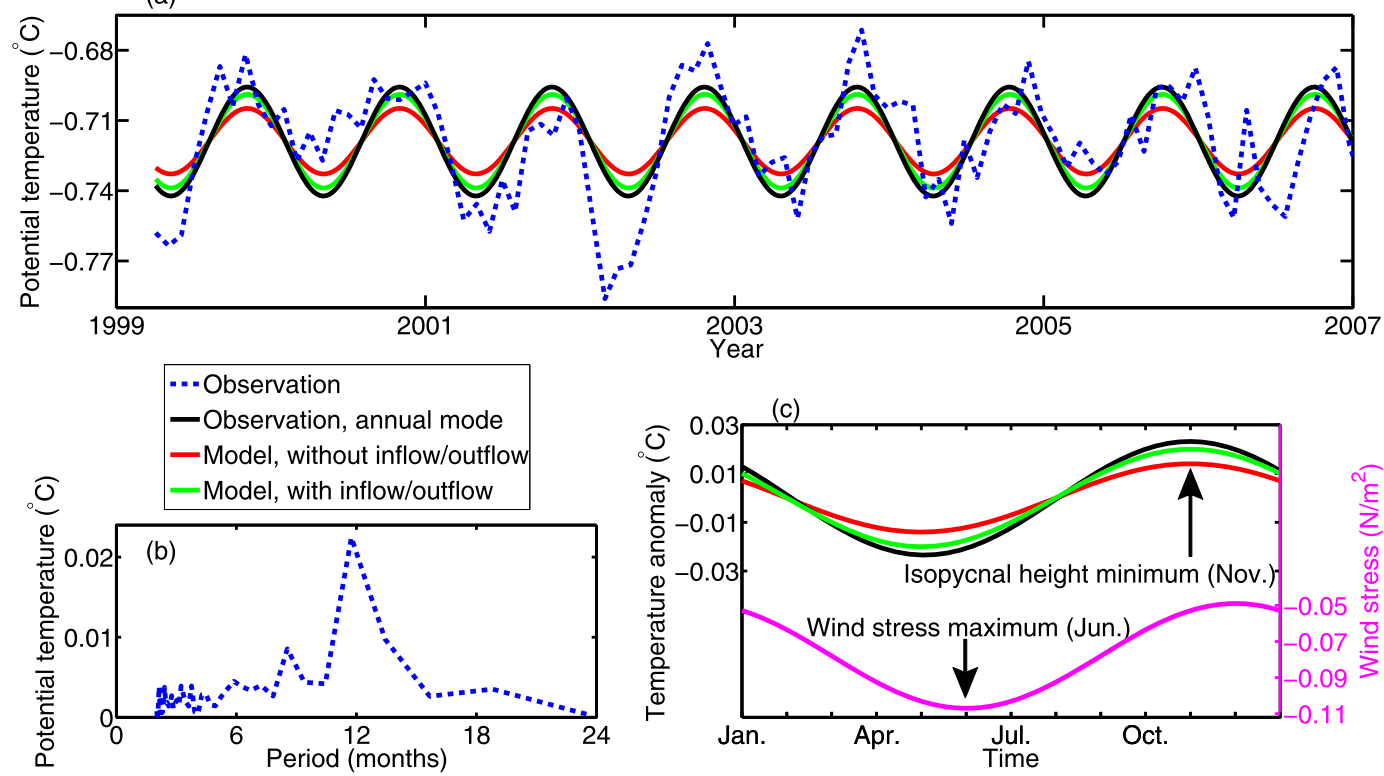

FIG. 10. (a) The 8-yr time series of potential temperature $\left({ }^{\circ} \mathrm{C}\right)$ of WSDW observed by sensor M3 moored in the northern boundary of the Weddell Sea (to the southeast of the South Orkney Islands) at $~ 4100-\mathrm{m}$ depth (Gordon et al. 2010). The blue dashed curve is the 30-day running mean, and the black solid curve is the annual mode. The red and green solid curves are derived from our model results with isopycnal oscillation amplitudes of 35 and $50 \mathrm{~m}$, respectively, at the gyre edge. The red solid curve corresponds to the case without inflow/outflow of WSDW with $\kappa=300 \mathrm{~m}^{2} \mathrm{~s}^{-1}$ and $\tau_{12}^{0}=-0.035 \mathrm{~N} \mathrm{~m}^{-2}$, as discussed in section $4 \mathrm{c}$. The green solid curve includes a time-dependent inflow of WSDW with $\alpha=4$ months and $\Gamma=6 \mathrm{~Sv}$, as discussed in section 5b. (b) The amplitude of the Fourier mode of observed potential temperature from (a) as a function of oscillation period. (c) Observed and modeled temperature oscillation, as in (a), plotted alongside the azimuthally averaged tangential wind stress at the shelf break, given by equation (2).

oscillation caused by the wind stress. As a result, the phase lag of the isopycnal oscillation is approximately 9 months in the gyre interior, whereas it was 3 months in the absence of a WSDW inflow/outflow. In contrast, the addition of WSDW inflow/outflow does not modify the phase lag in the gyre's boundary layer, but does increase its amplitude by about $5 \mathrm{~m}$.

Figure 9 shows that the time-mean isopycnal profile does not depend on $\Gamma$ and $\alpha$ because $\overline{\left[T_{i}-T_{o}(t)\right]}=0$. Both $\Gamma$ and $\alpha$ can significantly influence the isopycnal oscillation in the gyre interior, where their variability can modify the oscillation amplitude by $10-20 \mathrm{~m}$ and the oscillation phase by $2-3$ months. At the gyre boundary $\Gamma$ and $\alpha$ have little impact on the phase of isopycnal oscillation, but they contribute to the amplitude by $5-15 \mathrm{~m}$. In the reference case, $\Gamma=6 \mathrm{~Sv}$ and $\alpha=4$ months, the amplitude increases from 35 to $50 \mathrm{~m}$.

\section{Discussion}

\section{a. Comparison with data}

Though the model presented here is idealized, it is instructive to compare its predictions with the observed variability of WSDW in the boundary current upstream of the outflow from the Weddell Sea. At the boundary, isopycnals may experience a vertical isopycnal displacement on the order of $100 \mathrm{~m}$ due to the annual variability in the wind stress. We note here that vertical displacements on this scale may easily occur on much shorter time scales through tidal or internal wave fluctuations. The emphasis here is on the long-term shifts in the isopycnal depths. Mooring data provide the most reliable means to assess these annual changes in isopycnal depth.

An important contribution to our understanding of these fluctuations comes from the moored data collected in the northern boundary of the Weddell Sea (to the southeast of the South Orkney Islands) by Gordon et al. (2010). Figure 10a shows an 8-yr time series of the potential temperature of WSDW at $4100 \mathrm{~m}$ obtained at mooring M3. A 30-day running mean (blue dashed) and the annual mode (black solid) are shown. WSDW data at shallower depths are either unavailable or modified by mixing with warm deep water (Gordon et al. 2010). However, our scaling in section $4 \mathrm{a}$ indicates that the WSDW isopycnal oscillation at $4100 \mathrm{~m}$ should be similar to the WSDW isopycnal oscillation at $\sim 2000 \mathrm{~m}$. The data from $4100 \mathrm{~m}$ therefore serve as an approximate test of our model's predictions. 
The WSDW signal is dominated by the seasonal cycle (shown in Fig. 10b), which accounts for $\sim 80 \%$ of the total variability. Importantly, the annual cycle of potential temperature reaches its warmest values around November with a temperature change of about $0.047^{\circ} \mathrm{C}$ across one cycle. Our idealized model predicts that the boundary separating WSDW from CDW should be at its deepest, and so the water at $4100 \mathrm{~m}$ should be at its warmest, around November each year (see Fig. 5c). Our model closely captures the phase lag between annual wind stress variations and changes in WSDW properties at the boundary. Note that the phase of the oscillation at the gyre edge is a robust feature, being essentially independent of all model parameters.

Our model predicts that the temperature maximum close to the gyre boundary, where the moorings of Gordon et al. (2010) were situated, lags the wind stress maximum by 5 months. Yet Jullion et al. (2010) found a 5-month lag between the wind stress maximum and the WSDW temperature maximum in the Scotia Sea, which is 2-4-month transit time from the Weddell Gyre (Meredith et al. 2011). A plausible explanation takes into account that the phase varies rapidly across the gyre boundary layer. Thus, a mean phase lag across the boundary is closer to 3- or 4-month rather than the 5-month lag predicted at the gyre edge. Given that enhanced diapycnal mixing in the deep Scotia Sea will tend to smear any gradients of WSDW properties (Naveira Garabato et al. 2004), we estimate that the WSDW temperature maximum in the Scotia Sea should lag the wind stress maximum by 3 months plus the transit time through the Orkney Passage. This yields an estimate of 5-7-month lag between the wind stress maximum and the WSDW temperature maximum in the Scotia Sea, which is broadly consistent with the findings of Jullion et al. (2010).

Using typical parameters, our model predicts that the WSDW isopycnal should undergo a total vertical displacement of around $\sim 70-100 \mathrm{~m}$, as discussed in sections 4 and 5. For a typical temperature profile for the northern Weddell Gyre [e.g., see Fig. 1 of Gordon et al. (2010)] this corresponds to a temperature change of $0.028^{\circ}-0.04^{\circ} \mathrm{C}$ in the depth range $2-4 \mathrm{~km}$, spanning the core of WSDW (Gordon et al. 2001). Based on this estimate, the model explains $60 \%-85 \%$ of the amplitude in the moored data, shown in Figs. 10a and 10c. Within realistic parameter ranges, for example, an eddy diffusivity of $200 \mathrm{~m}^{2} \mathrm{~s}^{-1}$, a wind stress of $\tau_{12}^{0}=0.04 \mathrm{~N} \mathrm{~m}^{-2}$, and a time-dependent inflow/outflow with $\Gamma=4 \mathrm{~Sv}, \alpha=$ 4 months, the outcrop isopycnal displacement can reach $\sim 130 \mathrm{~m}$.

Our model only accounts for the mean and annual modes of the wind variability. However, Fig. $4 d$ shows that the semiannual mode may also make a significant contribution. Extending our analysis in section $2 b$, the semiannual mode of the wind stress can be approximated as $\tau_{6}^{0}(r / R) \cdot \sin \left(\omega_{6} t+11 \pi / 6\right)$, where $\tau_{6}^{0}=-0.011 \mathrm{~N} \mathrm{~m}^{-2}$ and $\omega_{6}=4 \pi \mathrm{yr}^{-1}$. If this mode is included in (2a), the isopycnal oscillation amplitude at the boundary increases by $10 \%-20 \%$, and its phase changes by roughly 10 days.

\section{b. Model limitations}

A number of important processes receive limited or no treatment in our current model. First, we assume that surface forcing comes from wind stress alone. In reality, buoyancy forcing, due to the growth and melt of sea ice and air-sea fluxes, also plays a critical role in driving seasonal fluctuations of the Weddell Gyre's stratification. This aspect merits further study. Our goal of developing a conceptual model of the Weddell Gyre led us to generate azimuthal averages of both wind stress and gyre bathymetry, whereas it is known that local bathymetric features can influence transport through modification of the boundary currents and cross-slope transport. The boundary geometry can also influence eddy diffusivities. These dynamics are only explored briefly in the current study, but in general are not well understood and are a topic of active research (Pennel et al. 2012; Stewart and Thompson 2013). Using observed wind data rather than reanalysis wind data might also improve the model, although at this level of idealization it would be unlikely to produce qualitatively different results.

The reanalysis surface winds from Large and Yeager (2009) do not account for modifications in momentum transport between atmosphere and ocean related to sea ice. Fujisaki et al. (2010) shows that the inclusion of sea ice always leads to an increase in stress at the ocean surface, within a range of $0 \%-50 \%$. This is true even if the sea ice concentration is $100 \%$ (see their Fig. 11b). Thus, our study may underestimate the wind stress magnitude in the Weddell Sea. Peaks in surface wind stress and Antarctic sea ice extent are offset by roughly 3 months (Polvani and Smith 2013) (maxima in June and September, respectively). Furthermore, sea ice coverage of the Weddell Gyre varies between roughly $50 \%$ and $100 \%$ in summer and winter, respectively (Parkinson and Cavalieri 2012). An extreme scenario would assume that sea ice always increases the effective wind stress by $50 \%$, leading to a gyre-averaged increase in wind stress of $\sim 25 \%$ in summer and $\sim 50 \%$ in winter. This modification enhances the wind stress annual mode amplitude by around $40 \%$ and shifts the wind stress peak by around two weeks. This is consistent with the upper end of the range of wind stress magnitudes examined in our sensitivity study in section 4 . While the coupling with sea ice is likely necessary for predicting the timing and properties 
of exported water masses, these changes do not fundamentally affect the dynamics discussed in this study.

In this study, we have specifically focused on seasonal variability. While our model dynamics would predict a long-term warming of exported Weddell waters in response to steadily increasing wind stress curl, we are cautious about extrapolating these results to decadal trends due to our poor understanding of mesoscale variability in these regions. It is conceivable that longterm trends in wind forcing may be compensated by enhanced eddy diffusivities as lateral gradients in the stratification adjust, as has been argued to occur in the ACC (Munday et al. 2013). A fixed eddy diffusivity is a poor representation of these dynamics. Furthermore, at longer time scales, baroclinic adjustment through Rossby waves (Anderson and Gill 1975), which are not included in this analysis, may become important. We suggest that longer-term variability should be investigated using an eddy-resolving model.

In section 5, the inflow/outflow of WSDW is assumed homogeneous in the whole domain. In reality, the effect of this inflow/outflow should be most pronounced close to the gyre boundary. We tested an alternative parameterization in which the inflow and outflow were localized to the radii spanned by the Orkney Passage, but found that it increased the oscillation amplitude at the gyre boundary by $\sim 10 \mathrm{~m}$ at most.

Accounting for diapycnal mixing may be expected to modify the isopycnal evolution equation (7), breaking mass conservation (9) in the WSDW layer. The dynamical significance of the diapycnal mixing term $\left(\kappa_{v}\langle b\rangle_{z}\right)_{z}$ in (3) may be estimated by comparing it to advection by the mean streamfunction $J(\langle\psi\rangle,\langle b\rangle)$ :

$$
J\left(\psi^{\dagger},\langle b\rangle\right)=\left(\kappa_{v}\langle b\rangle_{z}\right)_{z}
$$

For typical scales $z \sim 1000 \mathrm{~m}, r \sim 680 \mathrm{~km}, \tau \sim$ $0.03 \mathrm{~N} \mathrm{~m}^{-2}, f_{0} \sim 10^{-4} \mathrm{~s}^{-1}, \rho_{0} \sim 1000 \mathrm{~kg} \mathrm{~m}^{-3}$, and $\kappa_{v} \sim$ $10^{-5} \mathrm{~m}^{2} \mathrm{~s}^{-1}$ (Ledwell et al. 1993), we find that the ratio of diapycnal mixing to mean advection terms is around 0.02 . Thus, we expect the evolution of the isopycnal $z=$ $\eta(r, t)$ to be dominated by advection of the mean and eddy streamfunctions. If diapycnal mixing is enhanced $\kappa_{z} \sim 10^{-4} \mathrm{~m}^{2} \mathrm{~s}^{-1}$, then the ratio may be as large as 0.2 . However, close to the gyre edge the eddy advection term dominates the evolution of $\eta$ and is an order of magnitude larger than the mean advection, so we expect diapycnal mixing to have a minimal impact on our results.

\section{c. Model implications}

Our model indicates that an interplay between the wind stress and the mesoscale eddy fields may influence properties of exported WSDW. From a dynamical standpoint, this model has a number of similarities to recent work carried out in an Arctic context arguing for the importance of variability in boundary currents on the larger-scale circulation (Spall 2004). Our results remain consistent with a gyre interior that is governed by Sverdrup dynamics (Gordon et al. 1981). The novel aspect of this study points to the key adjustment to wind stress variability permitted by an energetic mesoscale eddy field at the gyre boundary. Representation of these wind and eddy contributions through RMT results in better agreement with observed isopycnal variability than could be achieved through classic adjustment via Rossby waves (Anderson and Gill 1975).

The mechanism via which the WSDW isopycnal achieves relatively large vertical displacements at the gyre boundary is somewhat counterintuitive and warrants further explanation. The annual component of the wind stress oscillates with almost uniform phase across the gyre, inducing either uniform upwelling or uniform downwelling depending on the season. From (6) we estimate that the time scale for the eddy response to this forcing over the radius of the gyre is $R^{2} / \kappa \sim 50 \mathrm{yr}$ for $\kappa=$ $300 \mathrm{~m}^{2} \mathrm{~s}^{-1}$, much longer than the 1 -yr time scale of the wind variations. We therefore expect the isopycnal oscillation to be dominated by the uniform wind-driven upwelling/downwelling. However, uniform upwelling or downwelling is prohibited by mass conservation (9), so a narrow gyre-edge boundary layer forms with an isopycnal oscillation opposing that in the gyre interior. The width of this boundary layer may again be estimated from (6) as $W_{\mathrm{bl}}=\sqrt{\kappa / \omega} \sim 40 \mathrm{~km}$.

As detailed in section $4 \mathrm{a}$, the annual component of the wind-driven vertical velocity is uniform and has a maximum amplitude of $\left|w_{\text {wind }}^{\prime}\right|=2 \tau_{12}^{0} /\left(\rho_{0} f_{0} R\right)$. Thus, the maximum wind-driven displacement of the isopycnal should scale as $\eta_{\text {wind }}^{\prime} \sim 2 \tau_{12}^{0} /\left(\rho_{0} f_{0} R \omega\right)$, which agrees with the analytical solution in the gyre interior (16a). It follows that the maximum wind-driven increase in mass beneath the isopycnal scales as $\Delta M_{\text {wind }} \sim \pi R^{2} \cdot \tau_{12}^{0} / \rho_{0} f_{0} R \omega$. To conserve mass, there must be an opposing eddy-driven displacement of the isopycnal $\Delta M_{\text {eddy }}=-\Delta M_{\text {wind }}$ in the boundary layer, which occupies a surface area of approximately $A_{\mathrm{bl}}=2 \pi R W_{\mathrm{bl}}$. Thus, the eddy-driven boundary layer isopycnal displacement should scale as $\eta^{\prime} \sim$ $-\Delta M_{\text {wind }} / A_{\mathrm{bl}} \sim-\tau_{12}^{0} /\left(\rho_{0} f_{0} \sqrt{\omega \kappa}\right)$, which agrees with our analytical solution for the boundary layer (16b). Because of the narrow boundary layer width $W_{\mathrm{bl}}$, the amplitude of the boundary layer oscillation is an order of magnitude greater than in the interior, $\left|\eta_{\text {eddy }}^{\prime} / \eta_{\text {wind }}^{\prime}\right| \sim 2 R \sqrt{\omega / \kappa} \approx 10$. This mechanism is illustrated in Fig. 11.

Our model shows that the representation of mesoscale eddy dynamics at the gyre boundary can significantly 


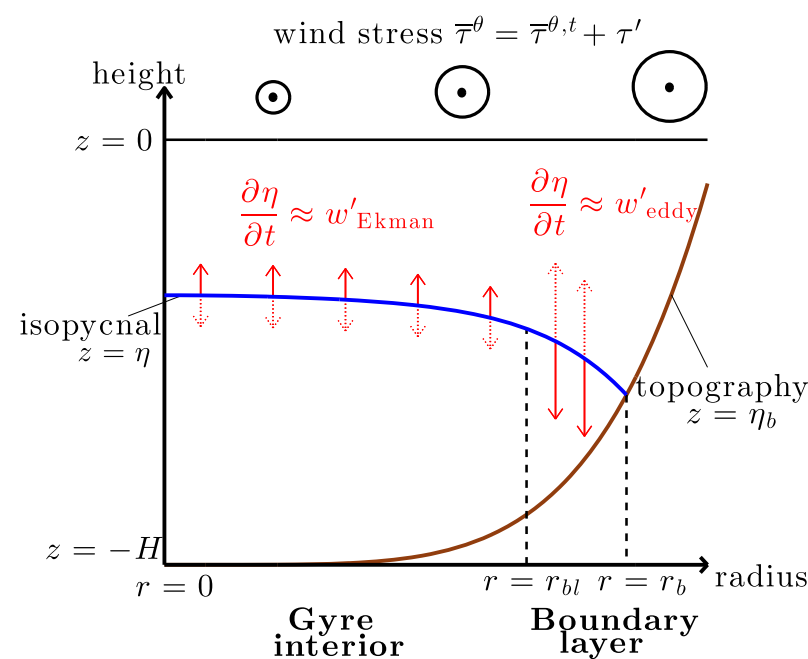

FIG. 11. Schematic of large-amplitude isopycnal oscillations generated at the gyre boundary. In the gyre interior, the isopycnal upwelling (downwelling) is controlled by Ekman pumping/suction driven by a uniform surface wind curl. To conserve the mass of the WSDW layer, mesoscale eddies act to downwell (upwell) the isopycnal in a narrow boundary layer. The boundary layer occupies a much smaller area of the isopycnal surface, so the amplitude of the oscillations is much larger than in the gyre interior. The boundary layer width is set by the strength of the mesoscale eddies and the frequency of the wind stress variability, which is predominantly annual.

impact the prediction of WSDW export. Eddy variability over sloping topography remains poorly understood (Stewart and Thompson 2013). Interactions with local bathymetric features, such as the Orkney Plateau, add further complications (Nøst et al. 2011). Resolving this variability in both models and observations is critical to arrive at a clearer description of Weddell Gyre dynamics and its contribution to the global meridional overturning circulation (MOC).

\section{Conclusions}

This study takes an idealized approach to the dynamics of the Weddell Gyre, motivated by recent evidence that mesoscale variability plays a key role in setting gyre properties and even global circulation properties. The key results are as follows:

(i) Using residual-mean theory, we develop an azimuthally averaged model of an idealized Weddell Gyre. Our model accounts for changes in the shape of the isopycnal separating WSDW from CDW due to the surface wind stress, eddy buoyancy fluxes, WSDW inflow from the Antarctic shelves, and WSDW outflow to the Scotia Sea.

(ii) The azimuthally averaged wind stress curl is approximately uniform and oscillates almost in phase, leading to a spatially uniform annual cycle of upwelling/downwelling driven by Ekman pumping. Mass conservation beneath the WSDW isopycnal requires that this oscillation be compensated by eddy-driven downwelling/upwelling in a narrow boundary layer, resulting in much larger isopycnal excursions close to the gyre edge.

(iii) Our model robustly predicts a phase lag of 5 months between the wind stress maximum and the density minimum at the gyre edge, which agrees closely with observations in the northern Weddell Sea (Gordon et al. 2010). For typical parameters the model's isopycnal oscillation explains at least 50\% of the amplitude of the observed temperature variations. This phase lag may be sensitive to modifications in surface momentum fluxes due to the seasonal sea ice coverage.

Acknowledgments. Z.S.'s research was supported NSF Award AST-1109299. A.L.S.'s and A.F.T.'s research was supported NSF Award OCE-1235488. We thank Arnold L. Gordon and Bruce Huber for providing the M3 mooring data and Alberto Naveira Garabato for useful conversations related to this study. We also thank two anonymous reviewers for helpful suggestions that improved the manuscript.

\section{APPENDIX A}

\section{The Isopycnal Evolution Equation}

Here, we derive an evolution equation for the azimuthally averaged isopycnal height $z=\eta(r, t)$ from the adiabatic residual-mean equations in a cylindrical basin. We start by noting that the residual velocity field is nondivergent by (4):

$$
\boldsymbol{\nabla} \cdot \mathbf{u}^{\dagger}=\frac{1}{r} \frac{\partial r u^{\dagger}}{\partial r}+\frac{\partial w^{\dagger}}{\partial z}=0 .
$$

Integrating (A1) from the ocean bed $z=\eta_{b}(r)$ to the WSDW isopycnal $z=(r, t)$ and applying Leibniz's rule (with square brackets indicating evaluation of an expression between two limits), we obtain

$$
\begin{aligned}
& \frac{1}{r} \frac{\partial}{\partial r}\left[r \int_{\eta_{b}(r)}^{\eta(r, t)} u^{\dagger} d z\right]-\frac{1}{r} \frac{\partial \eta}{\partial r}\left[r u^{\dagger}\right]_{z=\eta(r)} \\
& +\frac{1}{r} \frac{d \eta_{b}}{d r}\left[r u^{\dagger}\right]_{z=\eta_{b}(r)}+\left[w^{\dagger}\right]_{\eta_{b}(r)}^{\eta(r, t)}=0 .
\end{aligned}
$$

Equation (3) states that the azimuthally averaged buoyancy is materially conserved following the residual velocity, 
so fluid parcels located on the WSDW isopycnal $z=\eta(r, t)$ will always remain on that isopycnal, that is,

$$
\frac{D^{\dagger}}{D t}(z-\eta)=0 \quad \text { at } \quad z=\eta(r, t)
$$

where $D^{\dagger} / D t=\partial / \partial t+\mathbf{u}^{\dagger} \cdot \nabla$ is the residual-mean material derivative. As $w^{\dagger}=D^{\dagger} z / D t$, (A3) can be rewritten as

$$
\left.w^{\dagger}\right|_{z=\eta}=\frac{\partial \eta}{\partial t}+\left.u^{\dagger}\right|_{z=\eta} \frac{\partial \eta}{\partial r} .
$$

We also require that there be no flow normal to the ocean bed:

$\psi^{\dagger}=0, \quad$ or $\quad \mathbf{u}^{\dagger} \cdot \nabla\left(z-\eta_{b}\right)=0 \quad$ at $\quad z=\eta_{b}(r)$.

Using (A4) and (A5) to evaluate the rightmost term on the left-hand side of (A2), we obtain

$$
\frac{\partial \eta}{\partial t}=-\frac{1}{r} \frac{\partial}{\partial r}\left[r \int_{\eta_{b}(r)}^{\eta(r, t)} u^{\dagger} d z\right] .
$$

Finally, we use the definition $u^{\dagger}=-\partial \psi^{\dagger} / \partial z$ from (4) to evaluate the integral on the right-hand side of (A6) as

$$
\frac{\partial \eta}{\partial t}=\frac{1}{r} \frac{\partial}{\partial r}\left[\left.r \psi^{\dagger}\right|_{z=\eta(r, t)}\right] .
$$

\section{APPENDIX B}

\section{Numerical Scheme for a Curved Basin}

This appendix describes the numerical scheme for our residual-mean evolution equation (7). This derivation may be extended trivially to include the inflow and outflow of WSDW, as in (19). The outcrop position $r=$ $r_{b}(t)$ changes with time and must be tracked as part of the solution. To achieve this we perform a coordinate transformation from $r$ to

$$
\chi(r, t)=\frac{R}{r_{b}(t)} r .
$$

For convenience, we define the thickness of the WSDW layer as $h[\chi(r, t), t]=\eta[\chi(r, t), t]-\eta_{b}[\chi(r, t)]$. In $(\chi, t)$ coordinates' derivatives with respect to $r$ and $t$ may be evaluated using the chain rule as

$\left.\frac{\partial h}{\partial r}\right|_{t}=\left.\frac{R}{r_{b}} \frac{\partial h}{\partial \chi}\right|_{t}$ and $\left.\frac{\partial h}{\partial t}\right|_{x}=\left.\frac{\chi}{r_{b}} \frac{d r_{b}}{d t} \frac{\partial h}{\partial \chi}\right|_{t}+\left.\frac{\partial h}{\partial t}\right|_{r}$.

By substituting (B2) into (7), we obtain an evolution equation for the layer thickness $h$ in $(\chi, t)$ coordinates: $\left.\frac{\partial h}{\partial t}\right|_{X}=\frac{R}{r_{b}} \frac{1}{\chi} \frac{\partial}{\partial \chi} \chi\left(\frac{\tau}{\rho_{0} f_{0}}+\frac{R}{r_{b}} \kappa \frac{\partial \eta}{\partial \chi}\right)+\frac{\chi}{r_{b}} \frac{d r_{b}}{d t} \frac{\partial h}{\partial \chi}$.

The first term on the right-hand side of (B3) is simply the radial divergence of the residual vertical velocity, corresponding to the right-hand side of (7). The second term accounts for the fact that changing $r_{b}$ changes the mapping between $r$ and $\chi$ by (B1), leading to a mass redistribution in $(\chi, t)$ space. Note that $h(\chi=R, t)=0$ by definition, so $\partial h /\left.\partial t\right|_{\chi=R}=0$. Inserting this into (B2) we obtain an evolution equation for $r_{b}$ in $(\chi, t)$ space:

$$
\frac{d r_{b}}{d t}=-\left.\frac{\frac{\partial}{\partial \chi} \chi\left(\frac{\tau}{\rho_{0} f}+\frac{R}{r_{b}} \kappa \frac{\partial \eta}{\partial \chi}\right)}{R \frac{\partial h}{\partial \chi}}\right|_{x=R}
$$

Here, we have replaced $\chi$ with $R$ outside of derivatives with respect to $\chi$.

We solve numerically using a regular array of points $\left\{\chi_{i} \mid i=0, \ldots, N\right\}$, with $\chi_{0}=0$ and $\chi_{N}=R$. Equation (B3) provides an evolution equation for the layer thicknesses $\left\{h_{i} \mid i=0, \ldots, N-1\right\}$, and (B4) allows us to evolve the outcrop position $r_{b}$. We discretize all derivatives using second-order-centered finite differences. The boundary conditions (8a) and (8b) are used to set ghost points $\chi_{-1}$ and $\chi_{N+1}$ at each time step, allowing us to evaluate centered finite differences at $\chi_{0}$ and $\chi_{N}$. The grid resolution is $1 \mathrm{~km}$ and the time step is $960 \mathrm{~s}$, chosen to ensure that the Courant-Friedrichs-Lewy (CFL) condition is satisfied. We have verified that the numerical solution convergences under refinement of the numerical grid and also converges in parallel with a finite-volume scheme for the same equations. We present the results of the finite-difference scheme because it can track the outcrop position $r_{b}(t)$ with much greater accuracy, while closely conserving mass in the WSDW layer.

\section{APPENDIX C}

\section{Boundary Current Parameterization}

Beckmann et al. (1999) present model evidence from the Bremerhaven Regional Ice Ocean Simulations (BRIOS) GCM that the Weddell Gyre transport exhibits a pronounced annual cycle correlated with the local wind stress curl. Here we parameterize the western boundary current using the classic Stommel-Munk model for barotropic wind-driven gyre (Vallis 2006). We neglect the baroclinic component of the boundary current because the baroclinic adjustment timescale is on the order of years (Anderson and Gill 1975). We also 
note that the barotropic component dominates the transport close to the Orkney Passage due to the weak stratification (Naveira Garabato et al. 2002).

In the gyre interior, the wind stress curl drives a southward Sverdrup flow $\int u^{(y)} d z=\left(\boldsymbol{\nabla} \times \tau \hat{\mathbf{e}}_{\theta}\right) /\left(\rho_{0} \beta\right)$, where $u^{(y)}$ is the meridional velocity. In our model, this flow is spatially uniform because we impose an azimuthally symmetric wind stress with uniform curl $\nabla \times \tau \hat{\mathbf{e}}_{\theta}=\left.2 \tau\right|_{r=R} / R$ from (2a) to (2b). We represent the outflow of WSDW through the Orkney Passage by calculating the boundary current transport through a radial section $\theta=\theta_{\mathrm{OP}}, r>r_{\mathrm{OP}}$ across our idealized Weddell Gyre (see Fig. 2). We assume that the azimuthal western boundary current transport balances the total southward Sverdrup transport at the latitude of the Orkney Passage, $T_{\mathrm{Sv}}=\left.4 \cos \left(\theta_{\mathrm{OP}}\right) \tau\right|_{r=R} / \rho_{0} \beta$.

For simplicity, we approximate the boundary current as a spatially uniform azimuthal velocity at radii greater than $r=r_{\mathrm{bc}}$, which is assumed to encompass the Orkney Passage $r_{\mathrm{bc}}<r_{\mathrm{OP}}$. The azimuthal mass flux in the boundary current is $T_{\mathrm{bc}}=\int_{r_{c}}^{R} v_{\mathrm{bc}}\left(-\eta_{b}\right) d r$, where $v_{\mathrm{bc}}$, $T_{\mathrm{bc}}<0$ describes a cyclonic (northward) transport. Requiring that the Sverdrup and boundary current transports balance, $T_{\mathrm{Sv}}=T_{\mathrm{bc}}$, we obtain

$$
v_{\mathrm{bc}}=\frac{\left.4 \cos \left(\theta_{\mathrm{OP}}\right) \tau\right|_{r=R}}{\rho_{0} \beta \int_{r_{\mathrm{bc}}}^{R}\left(-\eta_{b}\right) d r} .
$$

The only unknown on the right-hand side of (C1) is the boundary current extent $r_{\mathrm{bc}}$. However, classic Stommel-Munk theory indicates that the boundary current width should be independent of the wind stress curl (Vallis 2006). Thus, given $r_{\mathrm{bc}}$ equation (C1) simply relates $v_{\mathrm{bc}}$ and $\left.\tau\right|_{r=R}$ via a constant of proportionality. Rather than try to parameterize $\theta_{\mathrm{OP}}$ and $r_{\mathrm{bc}}$ to match the geometry of the real Weddell Gyre, we instead take a typical boundary current speed for $v_{\mathrm{bc}}^{0}=-0.06 \mathrm{~m} \mathrm{~s}^{-1}$ from observations (Naveira Garabato et al. 2002) and assume that $r_{\mathrm{bc}}$ is sufficiently broad to accommodate the necessary transport $T_{\mathrm{bc}}$. We can therefore simplify $(\mathrm{C} 1)$ as

$$
v_{\mathrm{bc}}=v_{\mathrm{bc}}^{0}\left(1+\frac{\left.\tau_{12}\right|_{r=R}}{\left.\bar{\tau}\right|_{r=R}}\right) \text {. }
$$

\section{REFERENCES}

Abernathey, R. P., and J. Marshall, 2013: Global surface eddy diffusivities derived from satellite altimetry. J. Geophys. Res. Oceans, 118, 901-916, doi:10.1002/jgrc.20066.

,-- M. Mazloff, and E. Shuckburgh, 2010: Enhancement of mesoscale eddy stirring at steering levels in the Southern Ocean. J. Phys. Oceanogr., 40, 170-184, doi:10.1175/2009JPO4201.1.
Abramowitz, M., and I. A. Stegun, 1965: Handbook of Mathematical Functions with Formulas, Graphs, and Mathematical Tables. Dover Publications, 1046 pp.

Amante, C., and B. W. Eakins, 2009: ETOPO1 1 arc-minute global relief model: Procedures, data sources and analysis. NOAA Tech. Memo. NESDIS NGDC-24, 19 pp.

Anderson, D. L. T., and A. E. Gill, 1975: Spin-up of a stratified ocean, with applications to upwelling. Deep-Sea Res. Oceanogr. Abstr., 22, 583-596, doi:10.1016/0011-7471(75)90046-7.

Andrews, D. G., J. R. Holton, and C. B. Leovy, 1987: Middle Atmosphere Dynamics. Vol. 40. Academic Press, 489 pp.

Beckmann, A., H. H. Hellmer, and R. Timmermann, 1999: A numerical model of the Weddell Sea: Large-scale circulation and water mass distribution. J. Geophys. Res., 104, 23 375-23391, doi:10.1029/1999JC900194.

Deacon, G., 1979: The Weddell Gyre. Deep-Sea Res., 26A, 981995, doi:10.1016/0198-0149(79)90044-X.

Dinniman, M. S., J. M. Klinck, and W. O. Smith Jr., 2011: A model study of Circumpolar Deep Water on the west Antarctic Peninsula and Ross Sea continental shelves. Deep-Sea Res. II, 58, 1508-1523, doi:10.1016/j.dsr2.2010.11.013.

Fujisaki, A., H. Yamaguchi, and H. Mitsudera, 2010: Numerical experiments of air-ice drag coefficient and its impact on iceocean coupled system in the Sea of Okhotsk. Ocean Dyn., 60, 377-394, doi:10.1007/s10236-010-0265-7.

Gent, P. R., and J. C. McWilliams, 1990: Isopycnal mixing in ocean circulation models. J. Phys. Oceanogr., 20, 150-155, doi:10.1175/1520-0485(1990)020<0150:IMIOCM > 2.0.CO;2.

Gordon, A. L., D. G. Martinson, and H. W. Taylor, 1981: The winddriven circulation in the Weddell-Enderby Basin. Deep-Sea Res., 28A, 151-163, doi:10.1016/0198-0149(81)90087-X.

—, M. Visbeck, and B. Huber, 2001: Export of Weddell Sea deep and bottom water. J. Geophys. Res., 106, 9005-9017, doi:10.1029/2000JC000281.

—, B. Huber, D. McKee, and M. Visbeck, 2010: A seasonal cycle in the export of bottom water from the Weddell Sea. Nat. Geosci., 3, 551-556, doi:10.1038/ngeo916.

Isachsen, P. E., 2011: Baroclinic instability and eddy tracer transport across sloping bottom topography: How well does a modified Eady model do in primitive equation simulations? Ocean Modell., 39, 183-199, doi:10.1016/j.ocemod.2010.09.007.

Jullion, L., S. C. Jones, A. C. Naveira Garabato, and M. P. Meredith, 2010: Wind-controlled export of Antarctic Bottom Water from the Weddell Sea. Geophys. Res. Lett., 37, L09609, doi:10.1029/ 2010 GL042822.

Kida, S., 2011: The impact of open oceanic processes on the Antarctic Bottom Water outflows. J. Phys. Oceanogr., 41, 19411957, doi:10.1175/2011JPO4571.1.

Large, W. G., and S. G. Yeager, 2009: The global climatology of an interannually varying air-sea flux data set. Climate Dyn., 33, 341-364, doi:10.1007/s00382-008-0441-3.

Ledwell, J. R., A. Watson, and C. S. Law, 1993: Evidence for slow mixing across the pycnocline from an open-ocean tracer-release experiment. Nature, 364, 701-703, doi:10.1038/ 364701a0.

Locarnini, R. A., T. Whitworth, and W. D. Nowlin, 1993: The importance of the Scotia Sea on the outflow of Weddell Sea Deep Water. J. Mar. Res., 51, 135-153, doi:10.1357/ 0022240933223846.

Marshall, J., and T. Radko, 2003: Residual-mean solutions for the Antarctic Circumpolar Current and its associated overturning circulation. J. Phys. Oceanogr., 33, 2341-2354, doi:10.1175/ 1520-0485(2003)033<2341:RSFTAC >2.0.CO;2. 
McKee, D. C., X. Yuan, A. L. Gordon, B. A. Huber, and Z. Dong, 2011: Climate impact on interannual variability of Weddell Sea Bottom Water. J. Geophys. Res., 116, C5020, doi:10.1029/ 2010JC006484.

Mechoso, C. R., 1980: Baroclinic instability of flows along sloping boundaries. J. Atmos. Sci., 37, 1393-1399, doi:10.1175/ 1520-0469(1980)037<1393:BIOFAS > 2.0.CO;2.

Meredith, M. P., A. C. Naveira Garabato, A. L. Gordon, and G. C. Johnson, 2008: Evolution of the deep and bottom waters of the Scotia Sea, Southern Ocean, during 1995-2005. J. Climate, 21, 3327-3343, doi:10.1175/2007JCLI2238.1.

— A. L. Gordon, A. C. Naveira Garabato, E. P. Abrahamsen, B. A. Huber, L. Jullion, and H. J. Venables, 2011: Synchronous intensification and warming of Antarctic Bottom Water outflow from the Weddell Gyre. Geophys. Res. Lett., 38, L03603, doi:10.1029/2010GL046265.

Muench, R. D., and A. L. Gordon, 1995: Circulation and transport of water along the western Weddell Sea margin. J. Geophys. Res., 100, 18503-18515, doi:10.1029/95JC00965.

Munday, D. R., H. L. Johnson, and D. P. Marshall, 2013: Eddy saturation of equilibrated circumpolar currents. J. Phys. Oceanogr., 43, 507-532, doi:10.1175/JPO-D-12-095.1.

Naveira Garabato, A. C., E. L. McDonagh, D. P. Stevens, K. J. Heywood, and R. J. Sanders, 2002: On the export of Antarctic Bottom Water from the Weddell Sea. Deep-Sea Res. II, 49, 4715-4742, doi:10.1016/S0967-0645(02)00156-X.

- K. K. Polzin, B. A. King, K. J. Heywood, and M. Visbeck, 2004: Widespread intense turbulent mixing in the Southern Ocean. Science, 303, 210-213, doi:10.1126/science.1090929.

Nøst, O., M. Biuw, V. Tverberg, C. Lydersen, T. Hattermann, Q. Zhou, L. H. Smedsrud, and K. M. Kovacs, 2011: Eddy overturning of the Antarctic Slope Front controls glacial melting in the eastern Weddell Sea. J. Geophys. Res., 116, C11014, doi:10.1029/2011JC006965.

Orsi, A. H., and C. L. Wiederwohl, 2009: A recount of Ross Sea waters. Deep-Sea Res. II, 56, 778-795, doi:10.1016/ j.dsr2.2008.10.033.
Ou, H. W., 2007: Watermass properties of the Antarctic Slope Front: A simple model. J. Phys. Oceanogr., 37, 50-59, doi:10.1175/ JPO2981.1.

Parkinson, C. L., and D. J. Cavalieri, 2012: Antarctic sea ice variability and trends, 1979-2010. Cryosphere Discuss., 6, 931-956, doi:10.5194/tcd-6-931-2012.

Pedlosky, J., 1987: Geophysical Fluid Dynamics. Springer-Verlag, $710 \mathrm{pp}$.

Pennel, R., A. Stegner, and K. Béranger, 2012: Shelf impact on buoyant coastal current instabilities. J. Phys. Oceanogr., 42, 39-61, doi:10.1175/JPO-D-11-016.1.

Plumb, R. A., and R. Ferrari, 2005: Transformed Eulerian-mean theory. Part I: Nonquasigeostrophic theory for eddies on a zonal-mean flow. J. Phys. Oceanogr., 35, 165-174, doi:10.1175/ JPO-2669.1.

Polvani, L. M., and K. L. Smith, 2013: Can natural variability explain observed Antarctic sea ice trends? New modeling evidence from CMIP5. Geophys. Res. Lett., 40, 3195-3199, doi:10.1002/grl.50578.

Spall, M. A., 2004: Boundary currents and watermass transformation in marginal seas. J. Phys. Oceanogr., 34, 1197-1213, doi:10.1175/1520-0485(2004)034<1197:BCAWTI>2.0.CO;2.

Stewart, A. L., and A. F. Thompson, 2013: Connecting Antarctic cross-slope exchange with Southern Ocean overturning. J. Phys. Oceanogr., 43, 1453-1471, doi:10.1175/JPO-D-12-0205.1.

Stone, P. H., 1972: A simplified radiative-dynamical model for the static stability of rotating atmospheres. J. Atmos. Sci., 29, 405418, doi:10.1175/1520-0469(1972)029<0405:ASRDMF>2.0.CO;2.

Thompson, A. F., and K. J. Heywood, 2008: Frontal structure and transport in the northwestern Weddell Sea. Deep-Sea Res. I, 55, 1229-1251, doi:10.1016/j.dsr.2008.06.001.

Vallis, G. K., 2006: Atmospheric and Oceanic Fluid Dynamics: Fundamentals and Large-Scale Circulation. Cambridge University Press, 745 pp.

Wang, Q., S. Danilov, E. Fahrbach, J. Schröter, and T. Jung, 2012: On the impact of wind forcing on the seasonal variability of Weddell Sea Bottom Water transport. Geophys. Res. Lett., 39, L06603, doi:10.1029/2012GL051198. 